ORNL/TM-2015/8

\title{
Modeling and Simulation for Safeguards and Nonproliferation Workshop
}

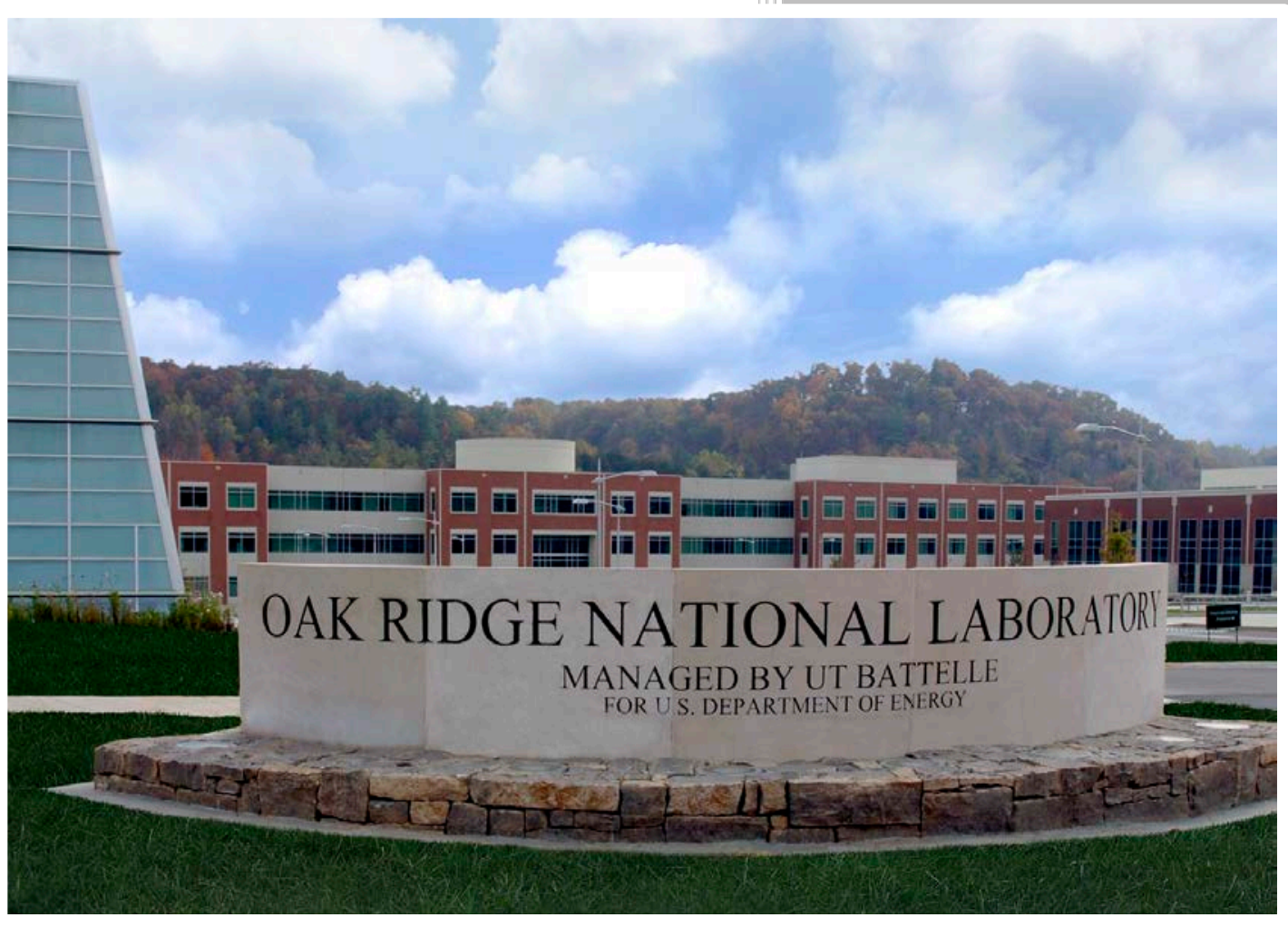

Kimberly Gilligan

Bernie Kirk

January 2015 


\section{DOCUMENT AVAILABILITY}

Reports produced after January 1, 1996, are generally available free via US Department of Energy (DOE) SciTech Connect.

Website http://www.osti.gov/scitech/

Reports produced before January 1, 1996, may be purchased by members of the public from the following source:

National Technical Information Service

5285 Port Royal Road

Springfield, VA 22161

Telephone 703-605-6000 (1-800-553-6847)

TDD 703-487-4639

Fax 703-605-6900

E-mail info@ntis.gov

Website http://www.ntis.gov/help/ordermethods.aspx

Reports are available to DOE employees, DOE contractors, Energy Technology Data Exchange representatives, and International Nuclear Information System representatives from the following source:

Office of Scientific and Technical Information

PO Box 62

Oak Ridge, TN 37831

Telephone 865-576-8401

Fax 865-576-5728

E-mail reports@osti.gov

Website http://www.osti.gov/contact.html

This report was prepared as an account of work sponsored by an agency of the United States Government. Neither the United States Government nor any agency thereof, nor any of their employees, makes any warranty, express or implied, or assumes any legal liability or responsibility for the accuracy, completeness, or usefulness of any information, apparatus, product, or process disclosed, or represents that its use would not infringe privately owned rights. Reference herein to any specific commercial product, process, or service by trade name, trademark, manufacturer, or otherwise, does not necessarily constitute or imply its endorsement, recommendation, or favoring by the United States Government or any agency thereof. The views and opinions of authors expressed herein do not necessarily state or reflect those of the United States Government or any agency thereof. 
Nuclear Security and Isotope Technology Division

Modeling and Simulation for Safeguards and Nonproliferation Workshop

Kimberly Gilligan

Bernie Kirk*

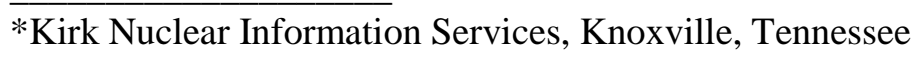

Date Published: January 2015

Prepared by

OAK RIDGE NATIONAL LABORATORY

Oak Ridge, Tennessee 37831-6283

managed by

UT-BATTELLE, LLC

for the

US DEPARTMENT OF ENERGY

under contract DE-AC05-00OR22725 



\section{CONTENTS}

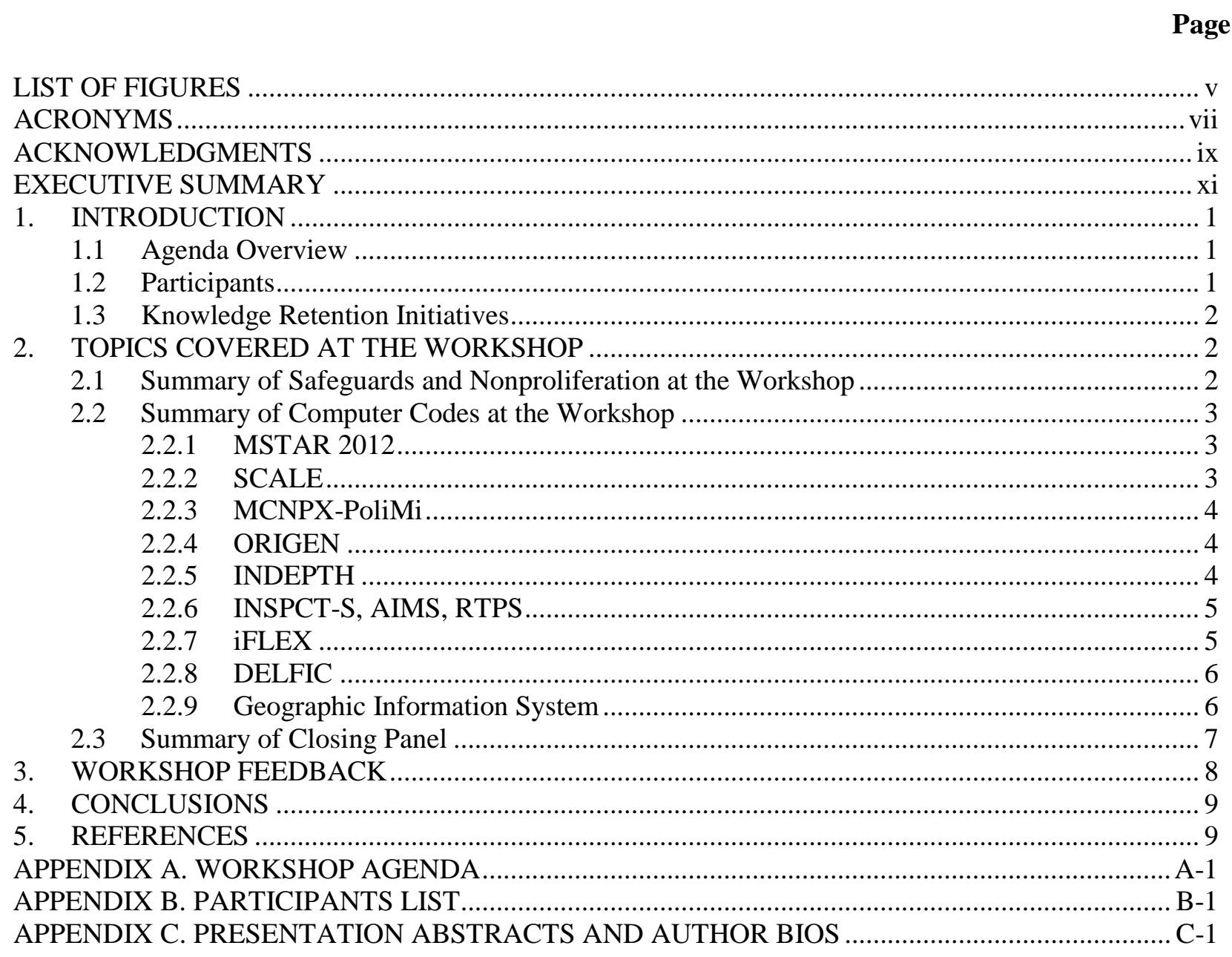





\section{LIST OF FIGURES}

Page

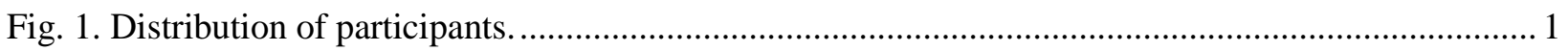

Fig. 2. Partial group photo of workshop participants............................................................................ 2 



\section{ACRONYMS}

AIMS Active Interrogation for Monitoring Special-nuclear-materials

BNL Brookhaven National Laboratory

CASL Consortium for Advanced Simulation of Light Water Reactors

CURIE Centralized Used Fuel Resource for Information Exchange

DELFIC Defense Land Fallout Interpretative Code

DOE US Department of Energy

GIS Geographic Information System

GT Georgia Institute of Technology

HCD Human capital development

HFIR High Flux Isotope Reactor

IAEA International Atomic Energy Agency

iFLEX incident Flux response EXpansion

INDEPTH Inverse Depletion Theory

INSPCT-S Inspection of Nuclear Spent fuel-Pool Calculation Tool - Spreadsheet

M\&S Modeling and Simulation

MCNP Monte Carlo N-Particle Code

NA-24 NNSA Office of Nonproliferation and Arms Control

NCSU North Carolina State University

NDA nondestructive analysis

NGSI Next Generation Safeguards Initiative

NNSA National Nuclear Security Administration

ORIGEN Oak Ridge Isotope Generation Code

ORNL Oak Ridge National Laboratory

PENTRAN Parallel Environment Neutral particle TRANsport

RTPS Real-Time spent fuel Pool Simulation

RSICC Radiation Safety Information Computational Center

SNM special nuclear material

TRAGIS Transportation Routing Analysis Geographic Information System

UF University of Florida

UM University of Michigan

UT University of Tennessee

UTK University of Tennessee, Knoxville

VT Virginia Polytechnic Institute and State University 



\section{ACKNOWLEDGMENTS}

The authors wish to thank the US Department of Energy's National Nuclear Security Administration Office of Nonproliferation and Arms Control (NA-24) for its support of the Human Capital Development projects since FY 2009, particularly staff members Dunbar Lockwood and Melissa Scholz for their encouragement and approval to continue the programs.

While the Modeling and Simulation for Safeguards and Nonproliferation Workshop took many dedicated people, special thanks are extended to Diana Tucker and Amy Hunt. The authors wish to extend an additional thanks to all of the presenters for their contributions. 



\section{EXECUTIVE SUMMARY}

The Modeling and Simulation for Safeguards and Nonproliferation Workshop was held December 15-18, 2014, at Oak Ridge National Laboratory. This workshop was made possible by the Next Generation Safeguards Initiative Human Capital Development (NGSI HCD) Program. The idea of the workshop was to move beyond the tried-and-true boot camp training of nonproliferation concepts to spend several days on the unique perspective of applying modeling and simulation (M\&S) solutions to safeguards challenges.

It is challenging to cover all topics of $M \& S$ that are implemented in nuclear safeguards and nonproliferation. The majority of material presented at the workshop was based on nuclear engineering, whereas nuclear applications span other scientific areas like physics, chemistry, and radiochemistry.

The International Atomic Energy Agency (IAEA) has a variety of M\&S projects, particularly associated with the nuclear fuel cycle. ${ }^{1}$ Numerous open literature publications are also available in which the use of computational models have been applied to nonproliferation and safeguards cases. ${ }^{2} \mathrm{M} \& \mathrm{~S}$ has been found to play a key role in validating experimental and measured data. In the absence of the latter, M\&S can be used in predicting future and past behavior.

During the 4 day workshop, 50 participants and speakers discussed past and current work. This included looking at past and current work funded at universities by NGSI as well as ways to utilize wellestablished software packages, such as those developed at ORNL. After a presentation on NGSI and the HCD program, the workshop began with a focus on safeguards to build a common base for the M\&S talks. The workshop then segued into M\&S currently used in safeguards and ongoing research projects.

The closing plenary session was a lively discussion representing academic and research perspectives. There was a consensus to invite more operations staff in the future to facilitate communication between those who need tools and those who develop them. There was also a desire to attract more students to a future workshop that could include break-out groups to brainstorm solutions to challenges presented by operations staff.

This workshop was a professional development opportunity for early and mid-career professionals. It also drew in new professionals to safeguards by offering a collaborative environment for M\&S professionals to apply their skills to nonproliferation. In attendance were individuals from a variety of backgrounds, ranging from graduate students to senior researchers. 



\section{INTRODUCTION}

The Modeling and Simulation for Safeguards and Nonproliferation Workshop was held December 15-18, 2014, at Oak Ridge National Laboratory. The diverse agenda offered presentations ranging from safeguards to modeling and simulation (M\&S). The objective was to highlight the harmony and value of M\&S with nonproliferation, specifically exploring current and potential applications in safeguards. A copy of the agenda is available in Appendix A.

\subsection{AGENDA OVERVIEW}

During the 4 day workshop, a wide range of research was presented. This included looking at past and current work funded at universities by NGSI, as well as looking at ways to utilize well-established software packages, like those developed at ORNL. Nuclear Security and Isotope Technology Division Director Cecil Parks opened the workshop with welcoming remarks that included a short history of the evolution of computing at ORNL. Next, a presentation on NGSI and the HCD program specifically was given. The workshop's first focus was on safeguards to build a common base for the M\&S talks. The workshop then segued into M\&S currently used in safeguards and ongoing research projects.

Participants were also given the option of touring the Consortium for Advanced Simulation of Light Water Reactors (CASL) and two safeguards laboratories or two reactors-the High Flux Isotope Reactor (HFIR) and the historic Graphite Reactor. A closing panel covering academic and research topics was held after the tours.

\subsection{PARTICIPANTS}

The 50 workshop participants and speakers were from universities, national laboratories, and the private sector. More specifically, eight professors and nine students represented eight different universities, eight participants were from national laboratories (not including ORNL staff and student workers), and three participants were from the private sector. The remaining 22 participants were ORNL researchers and student workers (Fig. 1).

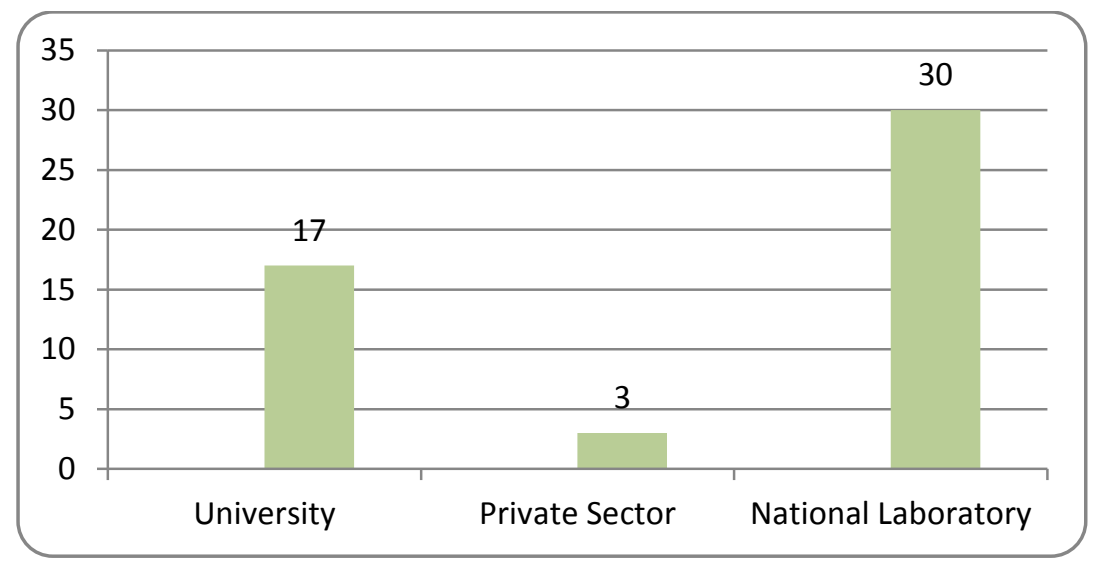

Fig. 1. Distribution of participants. 
Overall, the participants covered a wide range of career stages, from graduate students to very senior researchers. Several NGSI current and former interns participated, as well as NGSI mentors. A complete participants list with affiliations is provided in Appendix B. Approximately half the workshop participants and speakers are shown in Fig. 2.

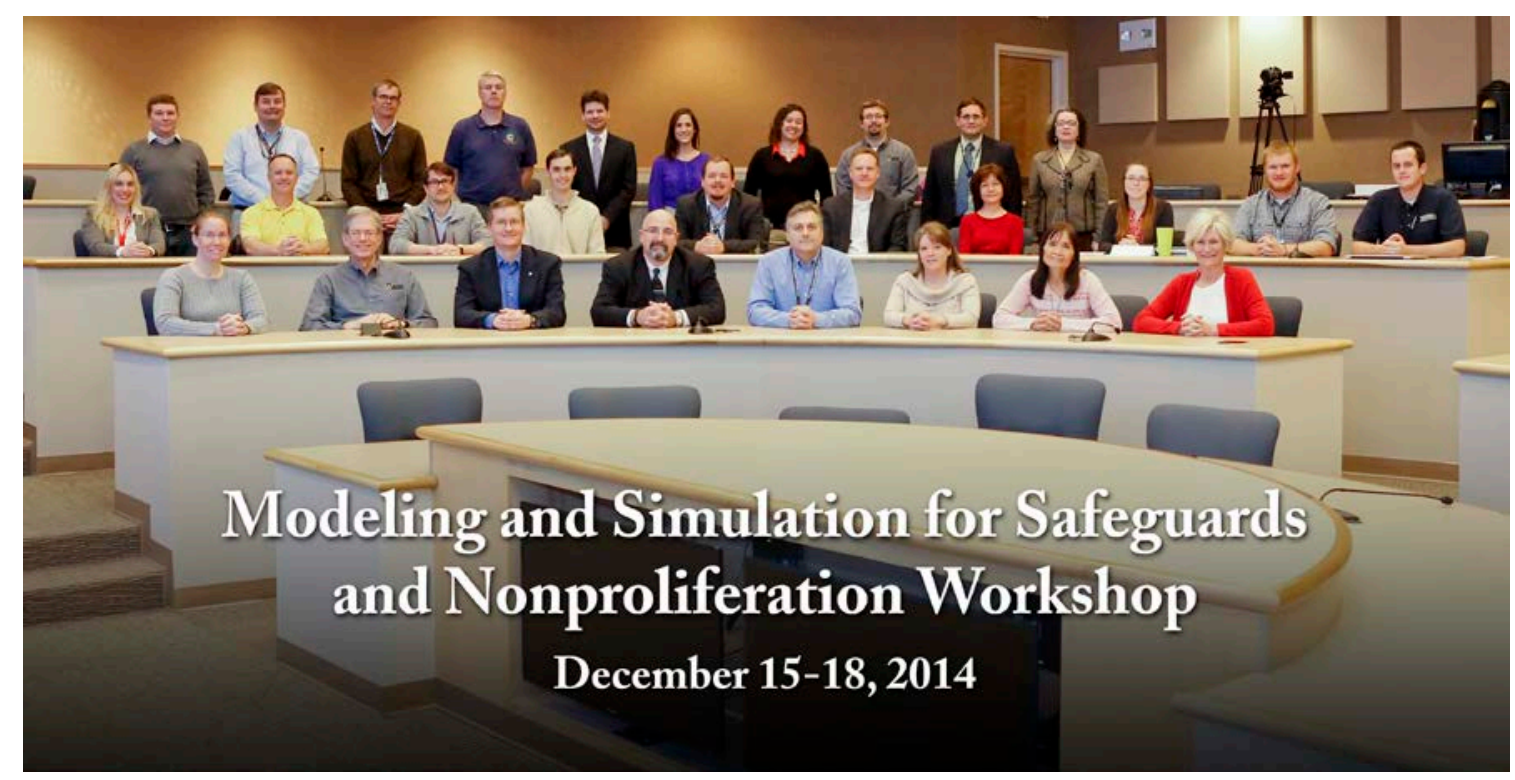

Fig. 2. Partial group photo of workshop participants.

\subsection{KNOWLEDGE RETENTION INITIATIVES}

A professional videographer digitally recorded the presentations and the closing panel for future viewing online. The reason for recording these presentations was twofold-first, to capture information on the existing and past projects as part of knowledge retention and knowledge management and, second, to serve as a resource for incorporation into university courses or for those who want to learn more about safeguards and M\&S, including domestic and international audiences.

This recording will be made available in the spring of 2015 through the NGSI cloud-based delivery project, which distributes NGSI-funded lectures and trainings online. Links will also be accessible from the new NGSI portal being created under the HCD roadmap project being spearheaded by ORNL and Brookhaven National Laboratory (BNL).

\section{TOPICS COVERED AT THE WORKSHOP}

A total of 26 talks were given on safeguards and M\&S. Appendix C includes an abstract for each presentation and the presenter's short biography.

\subsection{SUMMARY OF SAFEGUARDS AND NONPROLIFERATION AT THE WORKSHOP}

The safeguards presentations were given on the first day of the workshop. Michael Whitaker gave a talk on the evolution of nonproliferation and safeguards, followed by a complementary talk by Jim Garner on 
the role of the International Atomic Energy Agency (IAEA), including their roles beyond safeguards. Andrew Worrall gave a talk on the nuclear fuel cycle, allowing participants to put safeguards and M\&S in context. Jeff Chapman and Steven Croft gave talks on the uses of M\&S in safeguards, highlighting examples from past projects. They both emphasized the need to ensure that models are based on reality and are not a replacement for actual measurements. Finally, George Flanagan gave a presentation on design information verification, a key component of international safeguards, and the possibility of modeling facilities in the future as part of the verification effort.

On the second day, Chuck Weber shared a simulation developed for the IAEA that models enrichment cascades as one of the first examples of applying M\&S to a safeguards challenge. Two nuclear material accounting and control (NMAC) Y-12 staff, Leigh Cox and Ryan Holland, shared how they incorporate modeling into their daily tasks as safeguards professionals. Jessica White-Horton provided an overview of a database that ORNL has initiated; the database tracks M\&S projects, particularly the development of software. Josh Tackentien of BNL presented the use of virtual reality that allows users to actually be immersed in environments where nuclear facilities are scrutinized for safeguards implementation.

\subsection{SUMMARY OF COMPUTER CODES AT THE WORKSHOP}

The computer codes discussed by the participants represented only a handful of those widely used for safeguards application. The list below includes state-of-the art codes written in computer languages and tools that employ commercial off the shelf spreadsheet programs.

\subsubsection{MSTAR 2012}

Chuck Weber of ORNL has updated the original MSTAR software tool (originally written in Visual Basic) into MSTAR-2012 using FORTRAN. MSTAR-2012 is used in the study of uranium enrichment facilities, where cascading is a major process. Enrichment cascade modeling facilitates safeguards monitoring. MSTAR-2012 provides an approximate calculation of an ideal cascade, where the separation factor is independent of stage and assays are assumed equal.

\subsubsection{SCALE}

Brad Rearden presented the SCALE code system. SCALE is a comprehensive M\&S suite for nuclear safety analysis and design that is developed, maintained, tested, and managed by the Reactor and Nuclear Systems Division (RNSD) of Oak Ridge National Laboratory (ORNL). SCALE has over 6000 users from 54 countries and is distributed by the Radiation Safety Information Computational Center (RSICC). ${ }^{3}$

$\mathrm{SCALE}^{4,5}$ provides a comprehensive, user-friendly tool set for criticality safety, reactor physics, radiation shielding, radioactive source term characterization, and sensitivity and uncertainty analysis. For over 30 years, regulators, licensees, and research institutions around the world have used SCALE for safety analysis and design. SCALE provides a plug-and-play framework with 89 computational modules including three deterministic and three Monte Carlo radiation transport solvers that are selected based on the desired solution strategy. SCALE includes current nuclear data libraries and problem-dependent processing tools for continuous-energy and multigroup neutronics calculations, multigroup-coupled neutron-gamma calculations, as well as activation and decay calculations. SCALE also includes unique capabilities for automated variance reduction for shielding calculations, as well as sensitivity and uncertainty analysis. SCALE's graphical user interfaces assist with accurate system modeling and provide convenient access to desired results. 
Safeguards application of SCALE is prominent in the nuclear fuel cycle: material processing and fuel fabrication, tracking nuclear and research reactors, recycling, disposal, transportation and storage.

\subsubsection{MCNPX-PoliMi}

Shaun Clarke of the University of Michigan discussed the MCNPX-PoliMi code. ${ }^{6}$ Based on the original MCNP4C, the -PoliMi extension to MCNP $^{7}$ and to MCNPX was developed to simulate fission events and the subsequent interactions as close as possible to the physical behavior. In particular, neutron and photon fission multiplicity distributions have been implemented, and neutron interaction and photon production are correlated. At each collision, relevant information on neutron and gamma collisions is recorded, such as reaction type, target nucleus, energy deposited, time, and position. A post-processing code (MPPost) has also been developed and can be tailored to model specific detector characteristics. These features make the -PoliMi extension to MCNP and to MCNPX a versatile tool to simulate particle interactions and detection processes.

MCNPX-PoliMi is applicable in the safeguards detection of shielded special nuclear materials (SNM). MCNPX and MCNP-PoliMi are distributed by RSICC.

\subsubsection{ORIGEN}

Ian Gauld of ORNL discussed the current version of ORIGEN, which builds from the original as developed by Allen Croff. ORIGEN ${ }^{8}$ is an integral part of the SCALE system. ORIGEN is a fuel burnup analysis code that measures isotopic concentrations and activities, decay heat, radiation emission (neutron/gamma), and radiotoxicity.

ORIGEN applies a matrix exponential expansion model to calculate time-dependent concentrations, activities, and radiation source terms for a large number of isotopes simultaneously generated or depleted by neutron transmutation, fission, and radioactive decay. Provisions are made to include continuous nuclide feed rates and continuous chemical removal rates that can be described with rate constants for application to reprocessing or other systems that involve nuclide removal or feed. ORIGEN includes the ability to utilize multigroup cross sections processed from standard ENDF/B evaluations. Within SCALE, transport codes can be used to model user-defined systems, and the COUPLE code can be applied to calculate problem-dependent neutron-spectrum-weighted cross sections that are representative of conditions within any given reactor or fuel assembly and convert these cross sections into a library that can be used by ORIGEN. Time-dependent cross-section libraries may be produced that reflect fuel composition variations during irradiation. An alternative sequence for depletion/decay calculations is ORIGEN-ARP, ${ }^{9}$ which interpolates pre-generated ORIGEN cross-section libraries versus enrichment, burnup, and moderator density.

The updated capabilities in ORIGEN-ARP are well suited for safeguarding spent nuclear fuel, since the IAEA requires measurements to verify declared material quantities in spent nuclear fuel, particularly uranium and plutonium. With the large inventory of spent fuel assemblies, which continue to grow, M\&S with ORIGEN ensures an efficient method of verification. ${ }^{10}$

\subsubsection{INDEPTH}

Brandon Grogan of ORNL presented his work on the INDEPTH code, which was developed at the laboratory in order to reconstruct operating history parameters of a nuclear reactor from measurements of spent nuclear fuel or radioactive sources that are activated in a reactor. 
The operating history parameters in INDEPTH are reconstructed using a series of ORIGEN simulations as forward calculations. A gradient-based search technique guides the reconstruction toward the optimal solution using a weighted sum of squared errors (SSE) function to minimize the difference between the INDEPTH inputs and the ORIGEN forward calculation results. Input measurement options include isotopic content or ratios, gamma and/or neutron groups (flux), and gamma spectra from the fuel or irradiation target.

Several examples of INDEPTH reconstructions were presented by Grogan, including results from the recent Next Generation Safeguards Initiative - Spent Fuel (NGSI-SF) measurement campaign. Nuclear forensics is vital in the determination of proliferation activities. Knowledge of SNM helps in safeguards. INDEPTH allows one to understand the history of SNM (burnup, enrichment, time since irradiation, etc.) and its intended purpose. ${ }^{11}$

\subsubsection{INSPCT-S, AIMS, RTPS}

Ali Haghighat of Virginia Tech discussed accurate and fast software tools that use spreadsheets instead of established programming languages.

INSPCT-S ${ }^{12}$ was developed for calculating the response of fission chambers placed in a spent fuel pool. INSPCT-S is useful in the identification of suspicious regions of the pool that may have missing or substitute assemblies. It uses a hybrid algorithm based on the adjoint function methodology. The neutron source is comprised of spontaneous fission $(\alpha, n)$ interactions and subcritical multiplication. The former is evaluated using the ORIGEN-ARP code, and the latter is obtained with the fission matrix (FM)

formulation. The FM coefficients are determined using the MCNP Monte Carlo code, and the importance function is determined using the PENTRAN 3-D parallel $S_{n}$ code. Three databases for the neutron source, FM elements, and adjoint flux are prepared as functions of different parameters including burnup, cooling time, enrichment, and pool lattice size. INSPCT-S uses the aforementioned databases and systems of equations to calculate detector responses, which are subsequently compared with normalized experimental data. Thus, INSPCT-S provides fast identification of missing or moved fuel assemblies for safeguards inspection.

AIMS was developed as a fast and accurate particle transport methodology for simulation of active interrogation systems. It provides a quick calculation for the detection of SNM. AIMS involves four stages: (1) calculation of fission neutron density due to subcritical multiplication, (2) transport of fission neutron and gamma and generation of gamma source, (3) determination of gamma current at detector window, and (4) computation of detector response.

RTPS is another tool in development for spent fuel pools for criticality safety and safeguards verification. Monte Carlo calculations face convergence issues and long computation times, particularly under changing pool configurations. RTPS also uses the fission matrix approach to address these problems and allows for fast calculations.

\subsection{7 iFLEX}

Farzad Rahnema of Georgia Tech presented a new hybrid radiation transport method called COMET or $\mathrm{iFLEX}^{13}$ for on-the-fly detector calculations. IFLEX is fundamentally different from current stochastic and deterministic transport methods and their low-order approximations. The new method is capable of an accuracy comparable to Monte Carlo methods while achieving substantially reduced computation times. 
The iFLEX methodology is applicable to sensor design, optimization and diagnostics, image reconstruction, and material diversion and SNM detection. It provides a fast, efficient tool for active interrogation and has been applied to a simulated cargo container containing SNM.

\subsubsection{DELFIC}

Vince Jodoin of ORNL discussed his work on the laboratory's fallout M\&S program that incorporates DELFIC. DELFIC ${ }^{14}$ was originally intended for research in local nuclear fallout prediction and to serve as a standard against which predictions by less capable, production-oriented codes can be judged. Local fallout means the intensely radioactive material that falls to the ground within several to several hundred miles of ground zero, depending on the size of the explosion. DELFIC is able to predict the physical, chemical, and radiological properties of fallout debris.

Jodoin's group developed a Fallout Planning Tool that includes new graphical user interfaces for ORIGEN and DELFIC. ORIGEN was implemented into the Fallout Analysis Tool to predict the fallout source term nuclide inventory after the detonation of an improvised nuclear device (IND). DELFIC was incorporated into the Fallout Planning Tool and is used to predict the fractionated isotope concentrations in fallout, particle sizes, fractionation ratios, dose rate, and integrated dose over the planned collection routes-information vital to ensuring quality samples for nuclear forensic analysis while predicting dose to the sample collectors. DELFIC contains a particle activity module, which models the radiochemical fractionation of the elements in a cooling fireball as they condense into and onto particles to predict the fractionated activity size distribution for a given scenario. This provides the most detailed physics-based characterization of the fallout source-term phenomenology available in an operational fallout model.

\subsubsection{Geographic Information System}

GIS plays a key role in safeguards. The IAEA has published several documents in GIS and maintains programs to support the applicability of GIS ${ }^{15,16}$ in nuclear nonproliferation activities.

ORNL scientist, Budhendra Bhaduri, gave an overview of GIS projects (LandScan USA, LandScan Global, LandScan HD) and databases at the laboratory that are highly applicable to safeguards. TRAGIS ${ }^{17}$ and CURIE $^{18}$ are examples of such resources.

One of TRAGIS' main features is the ability to calculate routes that meet US Department of Transportation regulations for shipments of highway route controlled quantities of radioactive material. TRAGIS rail routing simulates actual rail routing practices and includes interchange locations between railroad systems. The model can automatically calculate alternative routes and allows the user to selectively block any node, link, and/or state in the routing networks. Population data, derived from ORNL's LandScan USA Interim data, is integrated with the transportation networks, so TRAGIS can provide route-specific population density information for transportation risk assessment analysis. TRAGIS has over 240 registered users spread throughout the federal government, DOE national laboratories, other federal subcontractors, and state, regional, and tribal representatives. New developments with the model include adding intermodal capabilities and improved GIS features.

The CURIE website is a national resource accessible to industry, vendor, federal, and laboratory partners, which provides usable, collaborative document and data access. It maintains an up-to-date calendar, used nuclear fuel (UNF) image gallery, featured documents, and external links to databases and websites. It also maintains the Siting Experience Database, which is a Blue Ribbon Commission on America's Nuclear Future (BRC) near-term recommendation. This database contains information from around the world related to the siting of a nuclear waste facility. 


\subsection{SUMMARY OF CLOSING PANEL}

The closing plenary session was a lively discussion representing academic and research perspectives. ORNL's International Safeguards Group Leader Michael Whitaker moderated the panel of six professors and two lab researchers. This included: Jeff Chapman, Ali Haghighat, Farzad Rahnema, John Mattingly, Katherine Goluoglu, Sedat Goluoglu, Steve Skutnik, and Ian Gauld.

There was a consensus that the presentations represented a "good breadth and depth of research and codes" as well as the workshop being a "great opportunity to see what research is being done and what is cutting edge” in the field. On that note, everyone agreed that an annual or bi-annual workshop to revisit the topic would be valuable. Changes to the future workshop format are noted below.

Because of the cutting-edge research shared, several professors expressed the desire to bring more students to a future workshop (in particular to include undergraduate students). One professor expressed her appreciation that the talks were recorded. She planned to share the recordings with the students and then arrange follow-up Q\&A sessions with the speakers via VTC.

Laboratory researchers and professors agreed that a future workshop should include more operations staff, such as the Y-12 speakers. The perspective of those in the field doing work is invaluable to researchers to understand real-world needs and priorities. It would also give operations staff an opportunity to see what tools are available to them that they may not have been aware of. A future workshop would facilitate communication between those who are using tools and those who are developing them.

On a related theme, discussion continued on designing user friendly tools. It does not matter how amazing the algorithms are if the tool is too difficult to use. There was mention that a user should not have to be a programmer to successfully use a tool. It is a waste of resources to develop a tool that is never used because the programmer did not consider the end user's perspective. It was also pointed out that not every user will have multiple processors or a super computer, so solutions that can run on a single processor are very valuable, especially for users in industry.

Also, just because a programmer has a powerful computer or specific hardware does not mean it necessarily needs to be used. Sometimes a simpler solution can be developed that will be useful to a wider audience. Also, developers need to explore a variety of options rather than try to fit a round peg in a square hole-just because Monte Carlo is available doesn't mean it needs to be used to resolve every issue.

There was disagreement between professional programmers who know how to code but don't understand the problems or physics and the professionals who know the problem and physics but don't understand the complexity of the coding, the opposing view being that truly interested engineers can learn to do the programming. Some schools already include courses on existing toolsets, although there is some debate on the value. It seemed more common for undergrads to take this type of course (which is seen as a marketable job skill) than for graduate students, who would be expected to develop their own simple codes to ensure a real understanding beyond "button pushing." It is the professor's prerogative as is seen in NGSI-supported curriculum.

Moving forward, there were several concrete proposals for future projects. It was suggested that a summary of research presented at the workshop be shared with users to elicit feedback to let them evaluate whether these tools help them perform their work and make suggestions for future tools or modifications. There may be a future proposal based on identifying users' challenges and prioritizing their needs. However, it was agreed that developers should always consider what tools are available rather than reinvent the wheel each project. In addition to generating proposals at the laboratories to solve real- 
world issues, the projects/challenges identified would be great opportunities to include in NGSI classes. For example, a user-identified challenge could be offered to as a class project in an NGSI-supported university course. This would let students use or develop M\&S tools to solve a real-world problem. They may have new creative viewpoints.

There was also the suggestion of a future project to develop a suite of safeguards problems for the modern tools like SCALE, MCNP, and MCNPX-PoliMi. Perhaps this would be a good project to bring for an NGSI funded student to support. One researcher saw these projects as an opportunity to raise awareness for sponsors of the efforts needed to develop, validate, and develop new technologies to support safeguards.

A monthly or bimonthly conference call to keep the momentum of the workshop going was also suggested. The consensus was that there is a need for an annual or biannual workshop on M\&S for safeguards and nonproliferation, but everyone agreed to move beyond sharing research to also include an opportunity to solve real-world problems. A future workshop should include current challenges users are facing (prior to presenting methods by developers). Then, after the researchers present their latest efforts, time should be allocated for at least a half-day breakout session to collaborate on solving a challenge presented by the users by applying what each researcher is working on. At the very least, the session would be valuable for all involved to best direct their efforts and begin exploring solutions. For some challenges, the solutions may be completed before the end of the workshop, for example, if it is a matter of determining what tool should be applied to a new challenge.

In summary, several new projects and paths forward were identified during the closing panel discussion. Each recommendation was worth further consideration, and the entire group wished to see these efforts continue.

\section{WORKSHOP FEEDBACK}

After concluding the workshop, participants were asked to submit feedback on their experiences. They were sent three open-ended questions:

1. What was most valuable about the workshop?

2. What improvement would you recommend?

3. Any other comments you wish to share?

Regarding the value of the workshop, participants indicated the breadth and diversity of the talks by bringing various aspects of safeguards; the 1hour given to each lecturer (allowing for more detail of the topic); the overall agenda; the mix of students, professors, and professionals; the overview talks on computational modeling providing history and abroad range of applications; and the closing panel. Improvements were suggested in the following areas: the inclusion of nuclear and radiochemical chemistry modeling since most of the talks were from nuclear engineers; engagement of modelers with end users and experimenters; computer codes to emphasize the actual applications; the need for roundtable discussions after each computer code presentation with a good mix of the audience (provide a summary of action items from roundtable); funding that will allow more university participation; and limiting WiFi accessibility, so attendees can focus. In addition, some indicated that networking was important, but they were not afforded the opportunity and suggested that sponsored events such as lunches and reception would help. Participants agreed that the workshop was a great experience and of value to their work and should be held with more student participation. 


\section{CONCLUSIONS}

The workshop was the first NGSI-sponsored event focusing on M\&S. Computing has become pervasive in life and has enabled scientists to model processes to a level that has never before been achieved. With the advances in high-performance computing and personal computers equipped with multi-processors, sophisticated simulations are now possible. The continued improvements and development of computer software will allow IAEA inspectors to perform calculations that will verify what nuclear facilities are doing, particularly with SNM. Detectors are becoming more sensitive and powerful.

Based on the response of the attendees, it is clear that there is a need to continue holding such workshops and promote the sharing of information on M\&S among both modelers and researchers. It is particularly important to get student involved, so the goals of NGSI HCD are fulfilled.

\section{REFERENCES}

1. https://infcis.iaea.org/NFCSS/NFCSSMain.asp?RightP=Modeling\&EPage=1

2. Tom Burr, Michael S. Hamada, John Howell, "Modelling And Simulation For Nuclear Material Accounting And Process Monitoring In Nuclear Safeguards”, IJRRAS 8 (3) September 2011.

3. http://rsicc.ornl.gov

4. https://scale.ornl.gov

5. Scale: A Comprehensive Modeling and Simulation Suite for Nuclear Safety Analysis and Design, ORNL/TM-2005/39, Version 6.1 (June 2011)

6. Sara A. Pozzi, Enrico Padovani, Marzio Marseguerra, "MCNP-PoliMi: a Monte-Carlo code for correlation measurements,” Nuclear Instruments and Methods in Physics Research Section A: Accelerators, Spectrometers, Detectors and Associated Equipment, Volume 513, Issue 3, 11 November 2003, Pages 550-558.

7. https://mcnp.lanl.gov

8. A. G. Croff, "A User's Manual for the ORIGEN2 Computer Code," ORNL/TM-7175 (July 1980).

9. S. M. Bowman and I. C. Gauld, OrigenArp Primer: How to Perform Isotopic Depletion and Decay Calculations with SCALE/ORIGEN, ORNL/TM-2010/43, Oak Ridge National Laboratory, Oak Ridge, Tenn., April 2010.

10. I. C. Gauld, S. M. Bowman and B. D. Murphy, "Application of ORIGEN to Spent Fuel Safeguards and Non-Proliferation," in Proc.of INMM 47th Annual Meeting, July 16-20, 2006, Nashville, Tennessee.

11. C. F. Weber and B. L. Broadhead, "Inverse Depletion/Decay Analysis Using the SCALE Code System," Trans. Am. Nucl. Soc. 95, 248-249 (2006).

12. William Walters, Alireza Haghighat, Shivakumar Sitaraman, Young Ham, Development of INSPCTS for Inspection of Spent Fuel Pool, Journal of ASTM International, Volume 9, Issue 4 (April 2012). 
13. Dingkang Zhang and Farzad Rahnema, “A fission collision separation method for efficient incident flux response expansion coefficient generation”, Annals of Nuclear Energy. 11/2014; 73:264-269.

14. DELFIC, Department of Defense Fallout Prediction System, Volume I - Fundamentals, Atmospheric Science Associates, Bedford, Massachusetts, December 31, 1979.

15. E. Wolfart et al, "GIS based Integration and Analysis of multiple source Information for NonProliferation Studies”, IAEA-CN-184/231.

16. J.G.M. Goncalves et al, "GIS based integration and analysis of multiple source information for nonproliferation studies”, IAEA-CN-184/231.

17. http://curie.ornl.gov/content/transportation-routing-analysis-gis-tragis

18. http://curie.ornl.gov/ 
APPENDIX A. WORKSHOP AGENDA 



\section{Modeling and Simulation for Safeguards and Nonproliferation Next Generation Safeguards Initiative}

Building 5100, JICS Auditorium

December 15-18, 2014

\begin{tabular}{|c|c|c|}
\hline \multicolumn{3}{|c|}{ Day 1 - Monday, December $15^{\text {th }}$} \\
\hline Time & Event & Speaker \\
\hline $8: 30-9: 00$ & Welcome and Safety Brief & $\begin{array}{l}\text { Cecil Parks (ORNL) and } \\
\text { Kim Gilligan (ORNL) }\end{array}$ \\
\hline $9: 00-9: 20$ & NGSI HCD & Kim Gilligan (ORNL) \\
\hline $9: 20-10: 20$ & $\begin{array}{l}\text { Evolution of Nonproliferation and } \\
\text { Safeguards }\end{array}$ & Michael Whitaker (ORNL) \\
\hline $10: 20-10: 40$ & COFFEE BREAK & \\
\hline $10: 40-11: 10$ & Role of the IAEA & Jim Garner (ORNL) \\
\hline $11: 10-12: 00$ & Nuclear Fuel Cycle Facilities Overview & Andrew Worrall (ORNL) \\
\hline $12: 00-1: 00$ & LUNCH & ORNL Cafeteria (on your own) \\
\hline $1: 00-1: 50$ & $\begin{array}{l}\text { Applying spent nuclear fuel modeling to } \\
\text { safeguards development }\end{array}$ & $\begin{array}{l}\text { Steve Skutnik (University of } \\
\text { Tennessee) }\end{array}$ \\
\hline $1: 50-2: 40$ & $\begin{array}{l}\text { The Role of Modeling and Simulation in } \\
\text { Nuclear Safeguards }\end{array}$ & Jeff Chapman (ORNL) \\
\hline $2: 40-3: 00$ & COFFEE BREAK & \\
\hline $3: 00-3: 50$ & Modeling and Simulation for NDA & Steven Croft (ORNL) \\
\hline $3: 50-4: 40$ & $\begin{array}{l}\text { Design Information Verification of } \\
\text { Nuclear Facilities }\end{array}$ & George Flanagan (ORNL) \\
\hline $4: 40-5: 10$ & Discussion: Needs and Opportunities & \\
\hline
\end{tabular}




\begin{tabular}{|c|c|c|}
\hline \multicolumn{3}{|c|}{ Day 2 - Tuesday, December $16^{\text {th }}$} \\
\hline Time & Event & Speaker \\
\hline $8: 00-8: 50$ & Modeling of Enrichment Cascades & Chuck Weber (ORNL) \\
\hline $8: 50-9: 40$ & $\begin{array}{l}\text { Modeling within Nuclear Materials } \\
\text { Control and Accountability (NMC\&A) }\end{array}$ & Leah Cox and Ryan Holland (Y-12) \\
\hline $9: 40-10: 10$ & $\begin{array}{l}\text { An Index of Modeling and Simulation } \\
\text { Activities at Oak Ridge National } \\
\text { Laboratory }\end{array}$ & Jessica White-Horton (ORNL) \\
\hline $10: 10-10: 30$ & COFFEE BREAK & \\
\hline $10: 30-11: 20$ & $\begin{array}{l}\text { Immersive Environment Development } \\
\text { for Training }\end{array}$ & Josh Tackentien (BNL) \\
\hline $11: 20-12: 10$ & $\begin{array}{l}\text { An Overview of the SCALE Computer } \\
\text { Code System }\end{array}$ & Brad Rearden (ORNL) \\
\hline $12: 10-1: 10$ & LUNCH & ORNL Cafeteria (on your own) \\
\hline 1:10-2:00 & $\begin{array}{l}\text { MCNPX-PoliMi Capabilities for Nuclear } \\
\text { Safeguards Applications }\end{array}$ & $\begin{array}{l}\text { Shaun Clarke (University of } \\
\text { Michigan) }\end{array}$ \\
\hline $2: 00-2: 50$ & $\begin{array}{l}\text { Application of ORIGEN for Improved } \\
\text { Spent Nuclear Fuel Safeguards }\end{array}$ & Ian Gauld (ORNL) \\
\hline $2: 50-3: 10$ & COFFEE BREAK AND GROUP PHOTO & \\
\hline $3: 10-4: 00$ & $\begin{array}{l}\text { High Flux Isotope Reactor HEU to LEU } \\
\text { Conversion - Reactor Physics Analyses }\end{array}$ & Germina Ilas (ORNL) \\
\hline $4: 00-4: 20$ & $\begin{array}{l}\text { Modeling and Simulation for } \\
\text { Safeguarding Enrichment Facilities }\end{array}$ & Jim Garner (ORNL) \\
\hline $4: 20-4: 50$ & Discussion: Needs and Opportunities & \\
\hline
\end{tabular}




\begin{tabular}{|c|c|c|}
\hline \multicolumn{3}{|c|}{ Day 3 - Wednesday, December $17^{\text {th }}$} \\
\hline Time & Event & Speaker \\
\hline 8:00-9:00 & $\begin{array}{l}\text { Inverse radiation transport problems for } \\
\text { Nondestructive Characterization of SNM }\end{array}$ & $\begin{array}{l}\text { John Mattingly (North Carolina } \\
\text { State University) }\end{array}$ \\
\hline 9:00-10:00 & $\begin{array}{l}\text { Gamma-Ray Validation Methods for } \\
\text { Safeguards Process Monitoring }\end{array}$ & Shaheen Dewji (ORNL) \\
\hline $10: 00-10: 20$ & BREAK & \\
\hline $10: 20-11: 20$ & INDEPTH Model of Spent Nuclear Fuel & Brandon Grogan (ORNL) \\
\hline $11: 20-12: 20$ & $\begin{array}{l}\text { Practical Application Exercises Using } \\
\text { SCALE for UF Safeguards Course }\end{array}$ & $\begin{array}{l}\text { Sedat Goluoglu (University of } \\
\text { Florida) }\end{array}$ \\
\hline $12: 20-1: 20$ & LUNCH & ORNL Cafeteria (on your own) \\
\hline $1: 20-2: 20$ & $\begin{array}{l}\text { Integrating Safety and Safeguards in } \\
\text { Design- The Role of Safety Analysis }\end{array}$ & $\begin{array}{l}\text { Katherine Goluoglu (University of } \\
\text { Florida) }\end{array}$ \\
\hline $2: 20-3: 20$ & $\begin{array}{l}\text { MRT Methodologies for Real-Time } \\
\text { Simulation of Nuclear Safeguards \& } \\
\text { Nonproliferation Problems }\end{array}$ & Ali Haghighat (Virginia Tech) \\
\hline $3: 20-3: 40$ & COFFEE BREAK & \\
\hline $3: 40-4: 40$ & $\begin{array}{l}\text { iFLEX Method for on-the-fly Detector } \\
\text { Calculations }\end{array}$ & Farzad Rahnema (Georgia Tech) \\
\hline $4: 40-5: 00$ & Discussion: Needs and Opportunities & \\
\hline
\end{tabular}




\begin{tabular}{|c|c|c|}
\hline \multicolumn{3}{|c|}{ Day 4 - Thursday, December $18^{\text {th }}$} \\
\hline Time & Event & Speaker \\
\hline 8:00-9:00 & $\begin{array}{l}\text { Defense Land Fallout Interpretive Code } \\
\text { (DELFIC): } \\
\text { Application to post-detonation nuclear } \\
\text { forensics }\end{array}$ & Vince Jodoin (ORNL) \\
\hline 9:00-10:00 & $\begin{array}{l}\text { Nuclear Operations and GIS: A Dynamic } \\
\text { Relationship }\end{array}$ & Budhu Bhaduri (ORNL) \\
\hline $10: 00-12: 00$ & $\begin{array}{l}\text { Tour 1: } \\
\text { - High Flux Isotope Reactor (HFIR) } \\
\text { - Graphite Reactor } \\
\text { Tour 2: } \\
\text { - Consortium for the Advanced } \\
\\
\text { Study of Light Water Reactors } \\
\text { (CASL) } \\
\text { - Safeguards Laboratories }\end{array}$ & \\
\hline $12: 00-1: 00$ & Lunch & ORNL Cafeteria (on your own) \\
\hline $1: 00-2: 30$ & $\begin{array}{l}\text { Panel } \\
\text { Michael Whitaker - Moderator }\end{array}$ & $\begin{array}{l}\text { Jeff Chapman, Ali Haghighat, Farzad } \\
\text { Rahnema, John Mattingly, } \\
\text { Katherine Goluoglu, Sedat Goluoglu, } \\
\text { Steve Skutnik, Ian Gauld }\end{array}$ \\
\hline $2: 30-3: 00$ & Wrap-up & \\
\hline
\end{tabular}


APPENDIX B. PARTICIPANTS LIST 



\begin{tabular}{|l|l|l|}
\hline Name & Affiliation & Email \\
\hline Alireza Haghighat & Virginia Tech & haghigha@vt.edu \\
\hline Andrew Worrall & ORNL & worralla@ornl.gov \\
\hline Arrielle Opotowsky & University of Wisconsin-Madison & $\begin{array}{l}\text { Arrielle.opotowsky@gmail.co } \\
\text { m }\end{array}$ \\
\hline Bernie Kirk & $\begin{array}{l}\text { Kirk Nuclear Information } \\
\text { Services }\end{array}$ & bern_kirk@att.net \\
\hline Bill Brosey & INMM Central & broseywd@att.net \\
\hline Bradley Rearden & ORNL & reardenb@ornl.gov \\
\hline Brandon Grogan & ORNL & groganbr@ornl.gov \\
\hline Budhendra L. Bhaduri & ORNL & bhaduribl@ornl.gov \\
\hline Cecil Parks & ORNL & parkscv@ornl.gov \\
\hline Christopher Cahill & George Washington University & cahill@gwu.edu \\
\hline Chuck Weber & ORNL & webercf@ornl.gov \\
\hline David Vermillion & UTK & dvermill@utk.edu \\
\hline Dawn Eipeldauer & ORNL Retired & deipeldauer@yahoo.com \\
\hline Diana Tucker & ORNL & tuckerdl@ornl.gov \\
\hline Emilie Fenske & UTK & efenske@vols.utk.edu \\
\hline Eric Rauch & LANL & ebrauch@lanl.gov \\
\hline Farzad Rahnema & GA Tech & farzad@gatech.edu \\
\hline George Flanagan & ORNL & flanagangf@ornl.gov \\
\hline Germina Ilas & ORNL & ilasg@ornl.gov \\
\hline Ian Gauld & ORNL & gauldi@ornl.gov \\
\hline Ike Therois & ANL & ike.therois@nnsa.doe.gov \\
\hline Jamie Baalis Coble & UTK & jcoble@utk.edu \\
\hline Jeff Chapman & ORNL & chapmanja@ornl.gov \\
\hline Jennifer Littell & UTK & jlittel1@vols.utk.edu \\
\hline Jessica White-Horton & ORNL & whitejl@ornl.gov \\
\hline Jianwei Hu & ORNL & hellojianwei@gmail.com \\
\hline Jim Garner & ORNL & garnerjr@ornl.gov \\
\hline John Mattingly & NCSU & john_mattingly@ncsu.edu \\
\hline Josh Tackentien & BNL & tackentien@bnl.gov \\
\hline Kara Thomas & George Washington University & cahill@gwu.edu \\
\hline Katherin Lee Goluoglu & UFL & klgoluoglu@mse.ufl.edu \\
\hline Kim Gilligan & gilligankl@ornl.gov \\
\hline
\end{tabular}




\begin{tabular}{|l|l|l|} 
Leah Cox & CNS & leah.cox@cns.doe.gov \\
\hline Matthew Cook & UTK & mcook4@vols.utk.edu \\
\hline Matthew Duchene & ORNL & duchenems@ornl.gov \\
\hline Michael Whitaker & ORNL & whitakerjm@ornl.gov \\
\hline Michael Willis & UTK & mwilli62@vols.utk.edu \\
\hline Nick Deroller & SRNL & nicholas.deroller@srnl.doe.gov \\
\hline Philip Makarewicz & ORNL & makarewiczpf@ornl.gov \\
\hline Rick Poland & SRNL & richard.poland@srnl.doe.gov \\
\hline Ryan Holland & CNS & ryan.holland@cns.doe.gov \\
\hline Scott Stewart & ORAU/ORNL & stewartsl@ornl.gov \\
\hline Sedat Goluoglu & University of FL & goluoglu@mse.ufl.edu \\
\hline Shaheen Dewji & ORNL & dewjisa@ornl.gov \\
\hline Shaun Clarke & University of Michigan & clarkesd@umich.edu \\
\hline Stephen Croft & ORNL & crofts@ornl.gov \\
\hline Steve Skutnik & UTK & sskutnik@utk.edu \\
\hline Thomas Pope & UTK & tpope3@utk.edu \\
\hline Troy Robinson & INL & troy.robinson@inl.gov \\
\hline Vincent Jodoin & ORNL & jodoinvj@ornl.gov \\
\hline & & \\
\hline
\end{tabular}


APPENDIX C. PRESENTATION ABSTRACTS AND AUTHOR BIOS 



\section{Contents}

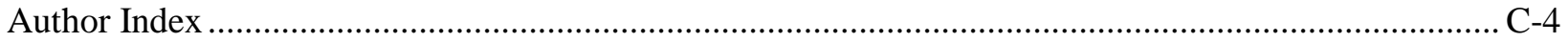

Nuclear Operations and GIS: A Dynamic Relationship ....................................................................... C-5

The Role of Modeling and Simulation in Nuclear Safeguards ................................................................6

MCNPX-PoliMi Capabilities for Nuclear Safeguards Applications........................................................ C-8

Modeling within Nuclear Materials Control and Accountability (NMC\&A)..........................................9

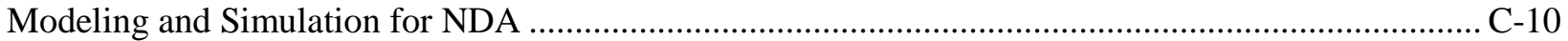

Gamma-Ray Validation Methods for Safeguards Process Monitoring................................................. C-11

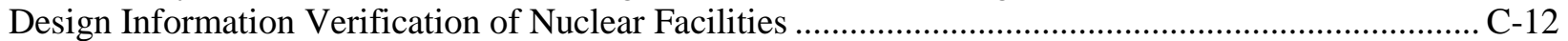

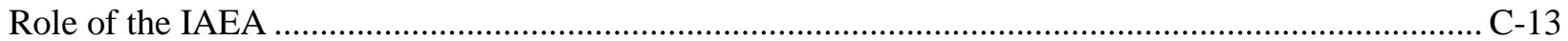

Modeling and Simulation for Safeguarding Enrichment Facilities..................................................... C-14

Application of ORIGEN for Improved Spent Nuclear Fuel Safeguards.............................................. C-15

ORNL Next Generation Safeguards Initiative (NGSI) Human Capital Development (HCD) ............... C-16

Integrating Safety and Safeguards in Design-The Role of Safety Analysis....................................... C-17

Practical Application Exercises Using SCALE for UF Safeguards Course........................................... C-18

INDEPTH Analysis of Spent Nuclear Fuel .................................................................................... C-19

MRT Methodologies for Real-Time Simulation of Nuclear Safeguards and Nonproliferation

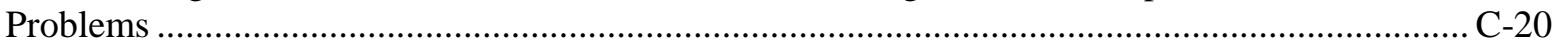

HFIR HEU-to-LEU Conversion-Reactor Physics Analyses ........................................................... C-21

Defense Land Fallout Interpretive Code (DELFIC): Application to Post-Detonation Nuclear

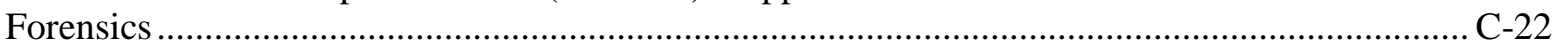

Inverse Radiation Transport Methods for Nondestructive Characterization of SNM ......................... C-23

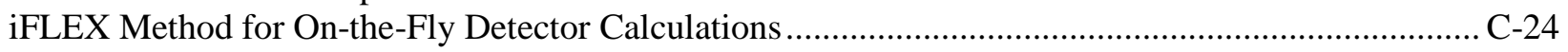

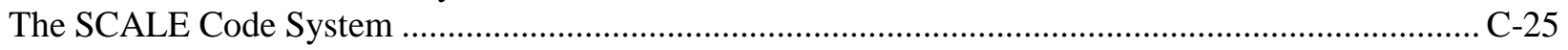

Applying Spent Nuclear Fuel Modeling to Safeguards Development................................................. C-26

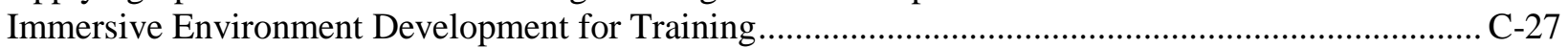

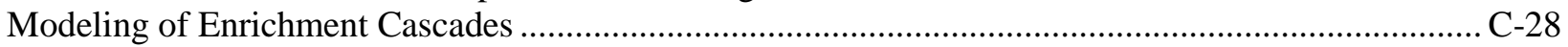

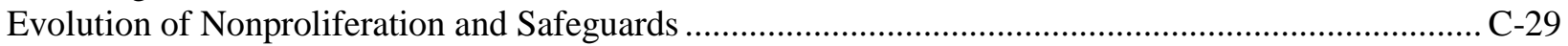

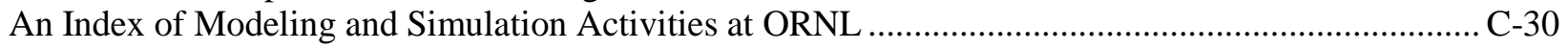

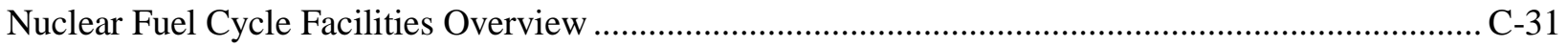




\section{Author Index}

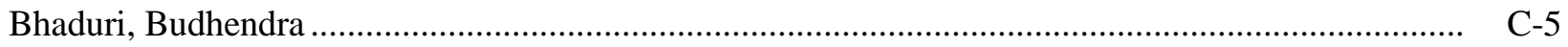

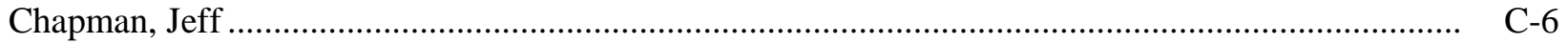

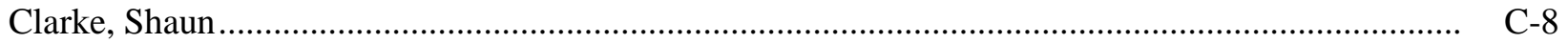

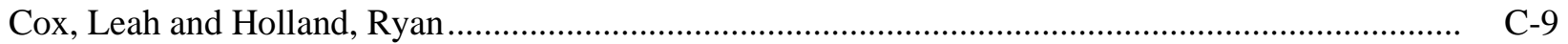

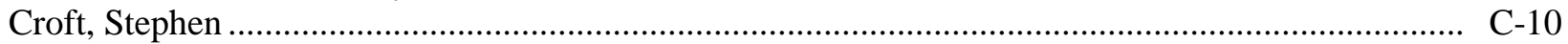

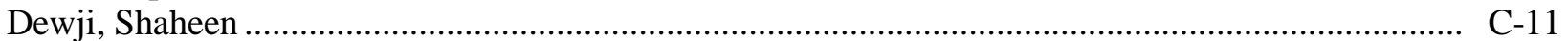

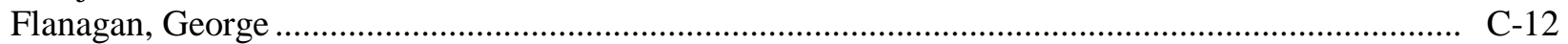

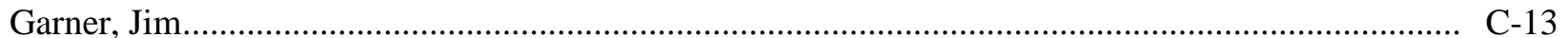

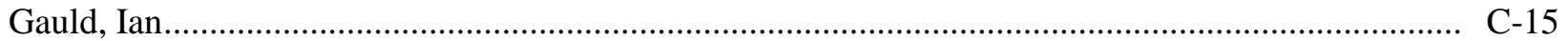

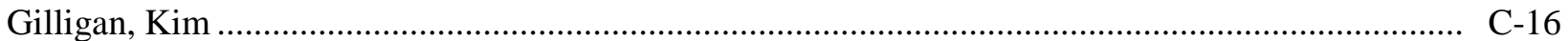

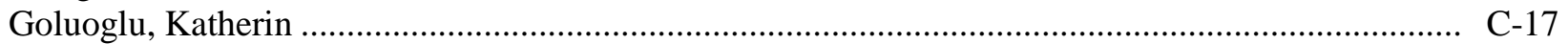

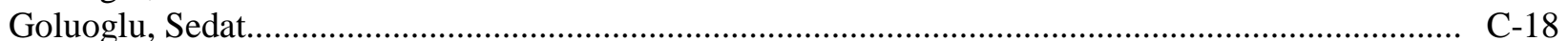

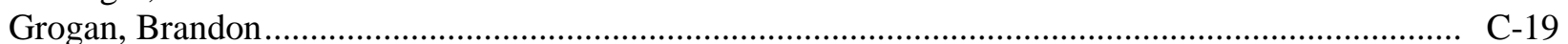

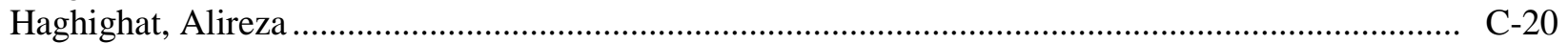

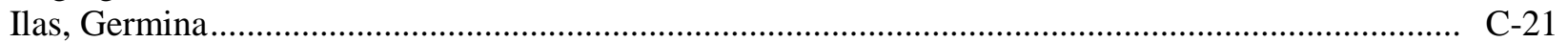

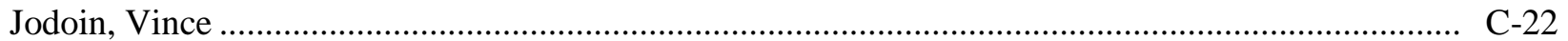

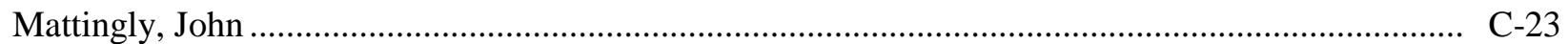

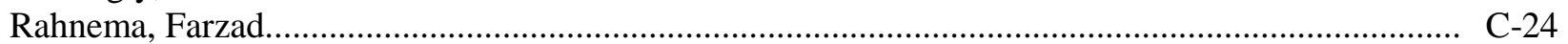

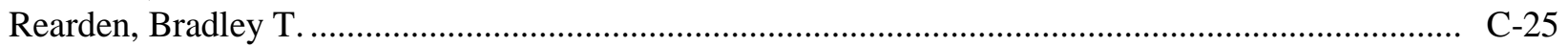

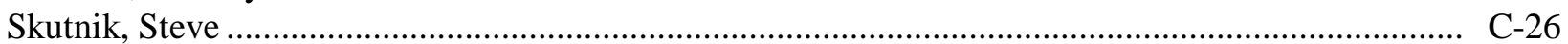

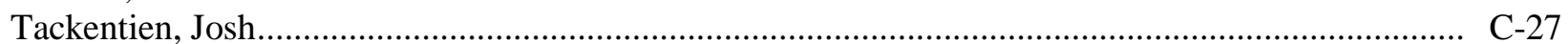

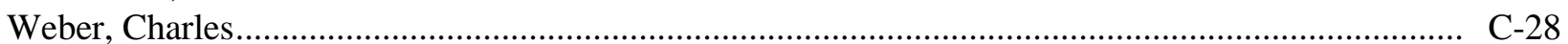

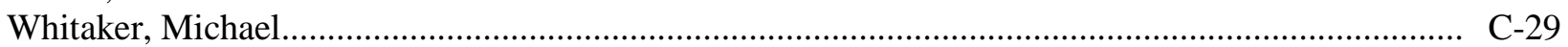

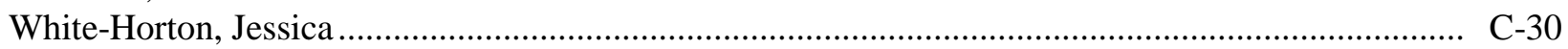

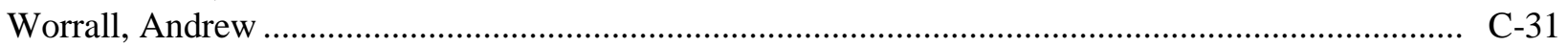




\title{
Nuclear Operations and GIS: A Dynamic Relationship
}

\author{
Budhendra Bhaduri \\ Corporate Research Fellow \\ Oak Ridge National Laboratory \\ bhaduribl@ornl.ogv \\ 865.241.9272
}

\begin{abstract}
Geographic Information Systems (GIS), based on the principles of Geographic Information Science (GIScience), has emerged as a powerful technology for exploration, analysis, synthesis, and presentation of geographic data that are observed (such as vegetation, critical infrastructures, hydrography), directly physically measured (such as temperature, geophysical parameters), and simulation output of physical and engineering systems (such as climate). Historically, nuclear science and technology have not only played an imperative role in the development of GIS as a technology and GIScience as a discipline; they have driven the progress of a number of modeling and simulation capabilities that have had a profound impact on other disciplines. This presentation will provide a narration of this relatively unknown history and illustrate the accomplishments, opportunities, and challenges of integrating dynamic and diverse geospatial information from earth observation or remote sensing data, various sensor networks, and spatial analyses using GIS-based modeling and simulation tools in time-critical operations, situational awareness, and decision support.
\end{abstract}

\section{BIOGRAPHY}

Budhendra Bhaduri is a Corporate Research Fellow of Oak Ridge National Laboratory and leads the Geographic Information Science and Technology group. His research interests and experience include novel implementation of geospatial science and technology in population dynamics modeling, natural resource studies, critical infrastructure protection, and disaster management. He is a founding member of the US Department of Energy's Geospatial Sciences Steering Committee and has served on the Mapping Sciences Committee of the National Academy of Sciences. Dr. Bhaduri holds a Ph.D. in Earth and Atmospheric Sciences from Purdue University. 


\title{
The Role of Modeling and Simulation in Nuclear Safeguards
}

Jeff Chapman

Distinguished Scientist (Nuclear Engineer)

Oak Ridge National Laboratory

ChapmanJA@ORNL.GOV

865.574.2728

www.ornl.gov

\begin{abstract}
In 1982, as I stood in line in the basement of Zachry Engineering Building at Texas A \& M, waiting to load my card decks for a radiation transport course taught by the late Ron Hart, I could not have imagined then how far we would come in advancing our computational capabilities. It's staggering. While Moore's law has become the cocktail party discussion for present-day computer jocks, I find it even more impressive how far the we've advanced with the human-machine interface, including a keyboard and monitor, much less a mouse! In the 1980s through 1990s, we hired many graduate students and postdocs just to run the computations we'd dream up (one per problem), and then of course to follow up with direct measurement, as we all knew that computers were not to be trusted. Not garbage in, garbage out. Rather, garbage in, gospel out. In the last 10 years, the role of computer modeling and simulation in nuclear safeguards has grown significantly. Most papers now at ANS, or INMM, involve some form of intercomparison between a direct measurement and a computer-calculated quantity. I'm afraid there may be a significant distortion evolving between what is physically achievable, from a measurement perspective, to that which is a calculated quantity. In the course of this presentation, I will cover several direct examples of projects where modeling and simulation allowed us to design a better "mouse trap," to optimize design for a measurement system, or allow us to estimate parameters from a set of fitting function that were poorly understood from the measurement data. Modeling and simulation certainly plays an important role in safeguards, but it must be tempered by the ability to perform physical measurements of the observable quanta.
\end{abstract}

\section{BIOGRAPHY}

Jeff joined ORNL as an undergraduate student studying Physics, in the winter of 1979, conducting neutron cross section measurements at the ORR. After graduating with his M.S. in Nuclear Engineering from Texas A\&M in 1983, he initially worked for Walter (Wally) Zinn, Kenneth Roach, Walt Mitchel and Stanley Turner in the Dunedin Florida office of Black and Veatch. You can google for yourself who these pioneers in nuclear engineering were. And it was there he began his career as a Nuclear Engineer, calling and driving back and forth to RSICC, discussing code development, methods, and application to the nuclear fuel cycle. In the early 1980s a number of projects for the US DOE were completedPlutonium Production in VVER-440 reactors; Criticality Studies of Graphite Moderated Reactors; Nuclear Winter; Production of ${ }^{238} \mathrm{Pu}$ in LWRs; Fuel Utilization; ${ }^{3} \mathrm{H}$ Handling at the Pinellas Plant-and for FPL— Fuel-Shuffle Schemes for LWRs and Spent-Fuel Rerack Calculations (the bread and butter at the time). There could have been no better way to get in the game. In 1986, immediately after the Challenger Accident, he moved to Rockwell International's Rocketdyne Division, in Canoga Park, CA, working for Bob Tuttle, who is currently working on his second book, entitled The Fourth Source of Energy. Bob studied under Richard Feynman at CalTech and was as every bit as brilliant. At the time, they were fully engaged in SDI projects, and efforts at both Rocky Flats and the Idaho Chemistry Plant, to help support SNAP Reactor Technology, and the fuel fabrication plant at DeSoto (where George Flanagan also used to work). In 1989, Jeff moved back to ORNL, so to speak, to work on his doctorate, 
and with the exception of a brief period in Connecticut at Canberra (2001-2005), he has been in Oak Ridge ever since. In the early days Jeff coded up his own home-grown codes to facilitate the estimation of measurable parameters, from fissionable material production in reactors, to solving eigenvalue problems associated with the differential die-away technique, to a long relationship with RSICC, since 1983.

Jeff has worked in nondestructive assay, test, and examination for most of his career, with matrixed stints to criticality safety, waste management, nuclear fuels, and health physics. He is a registered Professional Engineer and Certified Health Physicist, currently sitting on the American Board of Health Physics Part II Examination Panel. He has worked in nearly all of the US DOE facilities managing fissionable material in conjunction with MC\&A, Waste Management, and Security. 


\title{
MCNPX-PoliMi Capabilities for Nuclear Safeguards Applications
}

Shaun Clarke, Ph.D.

Assistant Research Scientist

University of Michigan

clarkesd@umich.edu

734.615.7830

http://dnng.engin.umich.edu

\begin{abstract}
The -PoliMi extension to the MCNP code has been used for the past decade to simulate the response of organic scintillation detectors, particularly for correlated-particle measurement. In 2011, this extension was made available through the Radiation Safety Information Computational Center (RSICC) as a patch to the MCNPX code, version 2.7.0, along with the associated detection post-processor, MPPost. MCNPPoliMi and MCNPX-PoliMi have been used for simulations across a spectrum of applications including nuclear nonproliferation and international safeguards. MCNPX-PoliMi has been used to design and optimize several systems based on correlated particle detection such as a liquid scintillator multiplicity counter and a neutron/gamma-ray imaging system. The design of these systems, and other safeguardsrelevant systems, relies on accurate simulation of event-by-event physics, a capability not present in the standard Monte Carlo codes. In addition, many safeguards systems rely on the detection of nuclear fission to verify declared materials, one key signature of which is correlated particle emissions.
\end{abstract}

\section{BIOGRAPHY}

Dr. Clarke received his Ph.D. in Nuclear Engineering from Purdue University in 2007 and afterwards joined the Department of Nuclear and Radiological Sciences at the University of Michigan where he is currently an Assistant Research Scientist and the Assistant Director for the NNSA-funded Consortium for Verification Technology. Dr. Clarke has more than 10 years of experience in Monte Carlo modeling and analysis of radiation detection systems, specifically with the codes MCNP4C, MCNP5, MCNPX, and MCNPX-PoliMi. Dr. Clarke also has several years of experience in radiation detection measurements. He has organized and performed international measurement campaigns involving measurements of special nuclear material with organic scintillation detectors and state-of-the-art digital electronics. Dr. Clarke is author or coauthor of more than 120 papers in conference proceedings and peer-reviewed journals. 


\title{
Modeling within Nuclear Materials Control and Accountability (NMC\&A)
}

Leah Cox and Ryan Holland

NMC\&A Statisticians

CNS Y-12, LLC

leah.cox@cns.doe.gov; ryan.holland@cns.doe.gov

865.576,8227; 865.576.8263

\begin{abstract}
Each individual in the nuclear materials industry has an obligation to practice proper material control. Avoiding theft and diversion of special nuclear material (SNM) not only ensures local and national security but also aids in efforts for nuclear nonproliferation. Many aspects of safeguards can be attributed to keeping material in safe hands.

Physical inventories and reconciliation allow sites to evaluate if they have what they say they have. Many different factors can play into the inventory difference of a particular period not equaling zero. A modeling approach can be taken to evaluate whether this inventory difference can be attributed to uncertainties in the estimates and measurements of the material or if other avenues need to be considered. Propagation of variance is the practice of combining components of variation to give an estimate of an acceptable range for the inventory difference.

Since physical inventories are only periodic, some type of monitoring should be available to catch realtime complications that arise. Process monitoring is the practice of breaking up processes into units and evaluating the ins and outs on a more granular level. Modeling is needed to gain an accurate picture of the process as well as estimate the effects of the process on the material.

Whether a physical inventory is taken once a year or an hourly process monitoring is required, modeling plays a crucial role in nuclear materials control and accountability. With proper documentation of assumptions, simple models can be an effective tool when accounting for SNM.
\end{abstract}

\section{BIOGRAPHY}

\section{Leah Cox}

B.S. Mathematics, Minor Secondary Education, University of Tennessee - Knoxville

M.S. Math Education, University of Tennessee - Knoxville

Math teacher for 3 years at West High School, Knox County

Statistician with NMC\&A for 7 years

Ryan Holland

B.S. Mathematics, University of Memphis

M.S. Business Analytics, University of Tennessee - Knoxville

Statistician with NMC\&A for 2 years 


\title{
Modeling and Simulation for NDA
}

Dr. Stephen Croft

Oak Ridge National Laboratory

crofts@ornl.gov

865.241.2834

\begin{abstract}
Active neutron interrogation can provide rapid nondestructive assay for certain hard-to-measure materials - such as uranium in a high-radiation environment. However, the results may be biased low because of self-shielding effects. We'll talk about this problem, how to quantify it by modeling, and how to apply the results in a practical setting.
\end{abstract}

\section{BIOGRAPHY}

Stephen is a Distinguished Nondestructive Assay Systems Scientist working in the Safeguards and Security Technology group at ORNL. He has broad research interests and experience in the areas of radiation metrology and uncertainty quantification applied to nuclear data, safety, security, international nuclear safeguards, and waste characterization. 


\title{
Gamma-Ray Validation Methods for Safeguards Process Monitoring
}

\author{
Shaheen Dewji \\ Research Staff \\ Oak Ridge National Laboratory \\ dewjisa@ornl.gov \\ 865.576.9348
}

ABSTRACT

In light of the evolution of nuclear technology, such as laser enrichment, as well as the emergence of new players in the production of uranium ore concentrate, recent International Atomic Energy Agency (IAEA) circulars and policy papers have explored implementing safeguards when any purified aqueous uranium solution or uranium oxides suitable for isotopic enrichment or fuel fabrication exist. Although safeguards have historically begun at the end of the conversion process with $\mathrm{UF}_{6}$ production, the new policies recommend that safeguards monitoring begin as early as the solvent extraction process in conversion. Work at the Uranyl Nitrate Calibration Loop Equipment (UNCLE) test-bed facility has focused on addressing nondestructive assay instrumentation challenges, with the overall goal of presenting a cohesive strategy integrating system-wide technologies as a technical basis for safeguarding natural uranium conversion facilities. Past work has been predicated on the development and testing of gross-neutron counting systems at NUCPs. However, given the limited supply of He-3 technology, low spontaneous fission emissions from UN, and detection challenges in operational settings, emphasis has shifted to focusing on evaluating gamma-ray signatures of uranyl nitrate. Through MCNPX simulation and experimental validation activities at UNCLE using $\mathrm{NaI}(\mathrm{Tl}), \mathrm{LaBr}_{3}$, and $\mathrm{HPGe}$ detectors, gamma-ray detector sensitivity measurements were conducted. The uncertainty and sensitivity variables affecting the detector response were propagated to determine whether IAEA detection goals can be met and interpreted as to how such sensitivities impact making broader safeguards decisions.

\section{BIOGRAPHY}

Shaheen Azim Dewji is a Nondestructive Assay Engineer in the Safeguards and Security Technology Group at Oak Ridge National Laboratory. She received her Ph.D. in the Nuclear and Radiological Engineering Program at the Georgia Institute of Technology, having studied at both the Atlanta, GA, and Metz, France, campuses. She received her B.Sc. in Physics from the University of British Columbia in 2006 and has participated in the Education Abroad Program at UC-Berkeley. She has completed a master's degree in Nuclear Engineering in 2009 at Georgia Tech in assaying internal contamination using hand-held radiation detectors in the event of a radiological dispersion device for the Centers for Disease Control and Prevention. From 2008-2009, Dewji was a Pre-Doctoral Fellow of the Sam Nunn Security Program at Georgia Tech. She further pursued her interests in nuclear security technical applications and nuclear security policy as a fellow of the Center for Strategic and International Studies "Nuclear Scholars Initiative” program. For 3 years, she interned at Oak Ridge National Laboratory through the Next Generation Safeguards Initiative program, collaborating on safeguards research projects associated with using nondestructive assay methods for plutonium quantification in spent nuclear fuel, as well as on gamma-ray detection methods for safeguards monitoring at natural uranium conversion facilities. Dewji is also a collaborator with ORNL’s Center for Radiation Protection Knowledge. 


\title{
Design Information Verification of Nuclear Facilities
}

\author{
Dr. George Flanagan \\ Distinguished Research Staff \\ Advance Reactor Systems and Safety Group, Reactor and Nuclear Systems Division, \\ Oak Ridge National Laboratory \\ flanagangf@ornl.gov \\ 865.574.8541
}

\begin{abstract}
One of the major processes used by the IAEA for safeguards is to ensure that the design of a nuclear facility is built and operated as specified by the member state. This is done by means of a design information verification or DIV. This is an evaluation and inspection process to ensure that the information supplied by the member state in the form of a design information questionnaire (DIQ) is correct and up to date. The lecture will provide information on the contents of the DIQ, how the information is related to safeguards, and how the DIV process is used to verify this information.
\end{abstract}

\section{BIOGRAPHY}

Dr. Flanagan teaches an annual course on Design Information Verification of Research Reactors to IAEA inspectors. He is a lecturer to the IAEA system state accountability and control course (SSAC) offered at ORNL every other year. He is also the author of the IAEA training manual on research reactors, critical facilities, and accelerator-driven neutron sources. Dr. Flanagan works on DOE- and NRC-sponsored projects with a focus on licensing, safety, and design of nuclear reactors. For over 15 years Dr. Flanagan was in charge of safety, safeguards, design, and experiments at the High Flux Isotope Reactor. He is the current chairman of the Standards Board of the American Nuclear Society and chairman of the International Standards Organization (ISO) reactor technology subcommittee. 


\title{
Role of the IAEA
}

\author{
Jim Garner \\ International Safeguards Research and Development Engineer \\ International Safeguards, Nuclear Security and Isotope Technology Division, \\ Oak Ridge National Laboratory \\ GarnerJR@ORNL.gov \\ 865.241.9983
}

\begin{abstract}
While the International Atomic Energy Agency (IAEA) may be best known for its role as the world's nuclear watchdog, its position as the Atoms for Peace organization within the United Nations family provides for a much broader scope. The IAEA is made up of five technical departments that address technical cooperation, nuclear energy, nuclear safety and security, nuclear science, and applications and safeguards. We will discuss some of the work these departments are performing and highlight some of the work that may be less well known.
\end{abstract}

\section{BIOGRAPHY}

Jim Garner joined the International Safeguards Group at Oak Ridge National Laboratory in 2010. Before joining Oak Ridge, Jim worked at the IAEA developing software for the Rokkasho Reprocessing Plant. His work focuses on developing new tools to assist in collecting and analyzing data from remotely monitored systems.

Jim received a bachelor's degree in Physics from Kenyon College, a bachelor's degree in Mechanical Engineering, and an MBA and master's degree in Computer Science from Washington University in St. Louis. 


\title{
Modeling and Simulation for Safeguarding Enrichment Facilities
}

\author{
Jim Garner \\ International Safeguards Research and Development Engineer \\ International Safeguards, Nuclear Security and Isotope Technology Division, \\ Oak Ridge National Laboratory \\ GarnerJR@ORNL.gov \\ 865.241.9983
}

\begin{abstract}
As uranium enrichment plants increase in number, capacity, and types of separative technology deployed (e.g., gas centrifuge, laser, etc.), more unattended, automated safeguards measures will likely be needed to enable the International Atomic Energy Agency (IAEA) to achieve safeguards objectives in a fiscally constrained environment. Monitoring load cell data can significantly increase the IAEA's ability to efficiently achieve the fundamental safeguards task of confirming operations as declared (i.e., no undeclared activities), but care must be taken to fully protect the operator's proprietary and classified information related to operations. Staff at ORNL, LANL, JRC/ISPRA, and University of Glasgow are investigating the monitoring of the process load cells at feed and withdrawal (F/W) stations to strengthen international safeguards at enrichment plants. A key question that must be resolved is, What is the necessary frequency of recording data from the process F/W stations? Several studies have analyzed data collected at a fixed frequency. While previous work has described an analysis of Monte Carlo simulations of feed cycles, this paper contributes to load cell process monitoring research by presenting an analysis of Monte Carlo simulations of product and tails withdrawal cycles to determine the expected errors caused by low-frequency sampling and its impact on material balance calculations.
\end{abstract}

\section{BIOGRAPHY}

Jim Garner joined the International Safeguards Group at Oak Ridge National Laboratory in 2010. Before joining Oak Ridge, Jim worked at the IAEA developing software for the Rokkasho Reprocessing Plant. His work focuses on developing new tools to assist in collecting and analyzing data from remotely monitored systems.

Jim received a bachelor's degree in Physics from Kenyon College, a bachelor's degree in Mechanical Engineering, and an MBA and master's degree in Computer Science from Washington University in St. Louis. 


\title{
Application of ORIGEN for Improved Spent Nuclear Fuel Safeguards
}

\author{
Ian Gauld \\ Distinguished R\&D Staff \\ Oak Ridge National Laboratory \\ gauldi@ornl.gov \\ 865.574.5257
}

ABSTRACT

Irradiated nuclear fuel is included in the range of nuclear materials considered by international safeguards as implemented in the framework of safeguards agencies and nonproliferation treaties because of its fissile material content. Developing improved and more efficient approaches to spent fuel safeguards is a priority in Europe because of the increasing number of spent-fuel-handling operations for dry storage as pools reach their capacities and as repositories in Finland and Sweden near operation. These activities require measurements to verify the nuclear material declarations. The nuclear content in spent fuel is usually not measured directly but can be inferred from nondestructive measurements using neutron and gamma-ray detectors. These measurements, routinely made using the Fork detector, currently represent the primary method of spent fuel safeguards used by EURATOM and the IAEA. Significant improvements have recently been achieved by analyzing the detector signals using detailed fuel irradiation and decay calculations performed by the ORIGEN code. These new methods are now being adopted by EURATOM and the IAEA. This talk will describe current safeguards approaches and requirements for spent fuel, new applications of ORIGEN to modeling and simulation for spent nuclear fuel safeguards, recent testing of the approach at the spent fuel facility in Sweden, and future advanced spent fuel measurement instruments currently being studied as part of the Department of Energy's Next Generation Safeguards Initiative (NGSI) Spent Fuel Project.

\section{BIOGRAPHY}

Ian Gauld is an R\&D staff member in the Reactor Physics group with 30 years of experience in spent nuclear fuel modeling and simulation. He joined Oak Ridge National Laboratory in 1999 and has managed the development of the ORIGEN (Oak Ridge Isotope Generation) code, used internationally for the analysis of spent fuel and radiation source terms used in safety and licensing analyses of nuclear facilities. Prior to joining Oak Ridge, Ian worked 14 years with Atomic Energy of Canada Ltd., where he led activities to standardize computer codes and nuclear data for spent fuel analysis for the Canadian Nuclear Industry (CANDU Owners Group). Ian has a master's degree in Physics from McMaster University and an undergraduate degree in Physics and Environmental Science from Trent University in Canada. He currently chairs the ANSI American National Standard working group on decay heat (ANS-5.1) and chairs the international OECD Nuclear Energy Agency Expert Group on Assay Data for spent nuclear fuel. 


\title{
ORNL Next Generation Safeguards Initiative (NGSI) Human Capital Development (HCD)
}

Kim Gilligan, Ph.D.

International Safeguards Group

Oak Ridge National Laboratory

giiligankl@ornl.gov

865.241.9287

\begin{abstract}
In 2007, the US Department of Energy National Nuclear Security Administration (DOE NNSA) Office of Nonproliferation and International Security (NA-24) completed a comprehensive review of the current and potential future challenges facing the international safeguards system. This review resulted in DOE NNSA launching a major new program to revitalize the international safeguards technology and human resource base. In 2007, at the International Atomic Energy Agency (IAEA) General Conference, then Secretary of Energy Samuel W. Bodman announced the newly created Next Generation Safeguards Initiative (NGSI). NGSI consists of five program elements:

* policy development and outreach,

* concepts and approaches,

* technology and analytical methodologies,

* human capital development (HCD), and

* infrastructure development.
\end{abstract}

\section{BIOGRAPHY}

Kimberly Gilligan is currently a nonproliferation specialist in the Nuclear Security and Isotope Technology Division at Oak Ridge National Laboratory (ORNL) and an adjunct professor of nonproliferation at Mercyhurst University. Gilligan received her B.S. from Rensselaer Polytechnic Institute (RPI) in Troy, NY, and her M.A. and PhD from Old Dominion University (ODU), in Norfolk, VA. Gilligan has held several prestigious nonproliferation fellowships, and in 2011 she was a fellow at the World Nuclear University in Oxford, United Kingdom. In addition, she has worked in international safeguards at the IAEA and Los Alamos National Laboratory (LANL). 


\title{
Integrating Safety and Safeguards in Design-The Role of Safety Analysis
}

\author{
Katherin Goluoglu \\ University of Florida \\ klgoluoglu@mse.ufl.edu \\ 352.273.2180 \\ http://www.nuceng.ufl.edu
}

\begin{abstract}
In designing new facilities and processes, it is important to recognize that safeguarding materials can sometimes present complications to the safety analyses required for that same material. During the design process then, it is important to understand that safety and safeguards as well as security must be considered together, rather than as three separate areas. In some cases, safeguards requirements may create challenges for criticality safety, while in other cases, a single requirement may benefit both disciplines. There are situations also where the modeling of a system for safeguards requirements does not meet the needs of the safety analysis, and vice versa. This discussion will review examples of how safety and safeguards can both contradict each other and complement each other, as well as strategies for integrating both aspects in the modeling and simulation of the proposed design.
\end{abstract}

\section{BIOGRAPHY}

Ms. Goluoglu is a nuclear engineer with over 17 years of experience in nuclear safety. Her experience includes providing technical and programmatic support to Oak Ridge National Laboratory (ORNL) Nuclear Criticality Safety (NCS) Program, the Uranium-233 Disposition Project, the Y-12 National Nuclear Security Complex, and the Yucca Mountain Project. Her responsibilities include performing NCS evaluations, verifying compliance with NCS approvals, reviewing operations and documentation, and providing technical, programmatic, and field support to assigned processes. She is currently a lecturer at the University of Florida, teaching radiation interactions with materials, criticality safety, safeguards, and radiation detection. 


\title{
Practical Application Exercises Using SCALE for UF Safeguards Course
}

\author{
Sedat Goluoglu \\ Professor \\ University of Florida \\ goluoglu@mse.ufl.edu \\ 352.294.1690 \\ goluoglu.mse.ufl.edu
}

ABSTRACT

The UF "Introduction to Safeguards" course provides engineering students with a brief background and overview of key topics important to nuclear materials safeguards, accountability, nonproliferation, and security. Students learn the fundamentals behind predicting, measuring, and accounting for nuclear materials of interest, and where additional research or capabilities are needed. The course culminates in practical exercises at Oak Ridge National Laboratory and in a joint exercise at the University of Florida that allows students to put these practices into real world applications. In addition, the students are asked to model a reactor system and simulate the depletion of materials. Students are also asked to investigate production of key isotopes of interest under different conditions such as power level, burn-up time, etc. This talk will focus on application of the SCALE computer code system to model and simulate a practical exercise from safeguards perspective.

\section{BIOGRAPHY}

Dr. Sedat Goluoglu is currently a professor in the Department of Materials Science and Engineering, Nuclear Engineering Program. Dr. Goluoglu received his Ph.D. in nuclear engineering from the University of Tennessee, Knoxville. Prior to joining the University of Florida, Dr. Goluoglu was a senior research and development staff at the Oak Ridge National Laboratory responsible for the development and implementation of continuous-energy Monte Carlo criticality, shielding, and depletion tools of the SCALE code system. His areas of expertise and interest include methods and code development for static and time-dependent neutron transport, reactor physics applications and methods development, radiation shielding methods development, nuclear criticality safety analyses and methods development, neutron and gamma cross section data processing methods and tools, sensitivity and uncertainty analyses and methods development. Dr. Goluoglu has been an active member of the American Nuclear Society since 1992. He has served in various capacities including Technical Program Chair, ANS 2013 Annual Meeting, Assistant TPC, ANS 2011 and 2012 Winter Meetings, Assistant General Chair, NCSD Topical Meeting, Knoxville, TN 2005. Dr. Goluoglu is a member of the OECD Nuclear Energy Agency (NEA), Nuclear Science Committee, Working Party on Reactor Systems, Expert Groups on Criticality Excursions Analyses and Burnup Credit Criticality. 


\title{
INDEPTH Analysis of Spent Nuclear Fuel
}

\author{
Brandon Grogan \\ Nuclear Chemical Engineer \\ ORNL \\ groganbr@ornl.gov \\ 865.576 .7468 \\ http://web.ornl.gov/sci/nsed/rnsd/group_nsm.shtml
}

\begin{abstract}
The Inverse Depletion Theory (INDEPTH) code was developed at the Oak Ridge National Laboratory (ORNL) in order to reconstruct operating history parameters of a nuclear reactor from measurements of spent nuclear fuel or radioactive sources that were activated in the reactor. The operating history parameters are reconstructed using a series of ORIGEN simulations as forward calculations. A gradientbased search technique guides the reconstruction toward the optimal solution using a weighted sum of squared errors (SSE) function to minimize the difference between the INDEPTH inputs and the ORIGEN forward calculation results. Input measurement options include isotopic content or ratios, gamma and/or neutron groups (flux), and gamma spectra from the fuel or irradiation target. Possible operating history parameters that can be reconstructed include the average power level, neutron flux, irradiation period, cooling time, initial uranium enrichment, and [for mixed-oxide (MOX) fuel] the initial plutonium content and Pu-239 vector. An overview of the INDEPTH methodology will be presented. Several examples of INDEPTH reconstructions will be presented, including results from the recent Next Generation Safeguards Initiative - Spent Fuel (NGSI-SF) measurement campaign.
\end{abstract}

\section{BIOGRAPHY}

Brandon Grogan received holds a BS in physics from West Point and a PhD in nuclear engineering from the University of Tennessee. From 2006 until 2011, Brandon worked with the Nuclear Materials Detection and Characterization group at ORNL as a grad student and postdoctoral researcher. His primary research focused on simulating active interrogation measurements of fissile materials using MCNP codes. He has been a nuclear chemical engineer with the Nuclear Security Modeling group at ORNL since 2011. His current research focuses on developing inverse methods for determining initial characteristics and operating parameters of nuclear fuel based on the analysis of spent fuel radiation signatures. 


\title{
MRT Methodologies for Real-Time Simulation of Nuclear Safeguards and Nonproliferation Problems
}

\author{
Alireza Haghighat \\ Professor \& Director \\ Virginia Tech \\ haghighat@vt.edu \\ 571.858.3333 \\ http://nsel.ncr.vt.edu
}

\begin{abstract}
The goal of the talk is to introduce the audience to novel Multi-stage, Response-function Transport (MRT) methodologies and tools for real-time simulation of problems in nuclear safeguards and nonproliferation.

In a MRT methodology, the problem of interest is partitioned into stages, and each stage is represented by a response function or set of coefficients. These stages are combined into a linear system of equations which are solved iteratively using the pre-calculated functions and/or coefficients. To determine these functions or coefficients, a set of fixed-source Monte Carlo and adjoint deterministic calculations are performed for different material compositions and physical/geometric conditions.

This paper will introduce a novel methodology, algorithm, and tool referred to as the INSPCT-S tool (INSPCT-S, Inspection of Nuclear Spent fuel-Pool Calculation Tool ver. Spreadsheet) developed for inspection of spent nuclear fuel pools. INSPCT-S uses computation and experimental results to identify potential fuel diversion in a spent fuel pool in real time. Further, the paper discusses the AIMS [Active Interrogation for Monitoring of Special Nuclear Materials (SNMs)] methodology and tool for simulation of an active interrogation system for detection of SNM. What is unique about these tools is the fact that computation is performed in real time while preserving the accuracy of 3-D transport calculations.
\end{abstract}

\section{BIOGRAPHY}

Dr. Alireza Haghighat is a professor in the Nuclear Engineering Program, Mechanical Engineering Department at Virginia Tech (VT)and the Director of Nuclear Science and Engineering Lab (NSEL) at the Virginia Tech Research Center (VTRC) at Arlington. He is the former Chair (2001-2009) of the Nuclear \& Radiological Engineering (NRE) Department of the University of Florida and the former Director (2008-2010) of the University Florida Training Reactor (UFTR). Prior to the University of Florida, Dr. Haghighat was a faculty member at the Pennsylvania State University for 15 years.

Dr. Haghighat is a fellow of the American Nuclear Society (ANS) and is director of the Virginia Tech Theory Transport Group $\left(\mathrm{VT}^{3} \mathrm{G}\right)$. Over the past 27 years, he has been involved in the development of new particle transport computational methodologies and large computer codes for modeling and simulation of nuclear systems including reactors, nuclear security and safeguards systems, and medical devices. He has published over 230 papers and received several best paper awards. He is also the recipient of the 2011 Radiation Protection Shielding Division's Professional Excellence Award and a recognition award from Office of Global Threat Reduction for his leadership and contributions to design and analysis for the University of Florida Training Reactor HEU to LEU fuel conversion (2009). 


\title{
HFIR HEU-to-LEU Conversion-Reactor Physics Analyses
}

Germina Ilas

Senior R\&D Staff

Reactor and Nuclear System Division, Oak Ridge National Laboratory

ilasg@ornl.gov

865.241.4672

\begin{abstract}
An engineering design study of the conversion of the High Flux Isotope Reactor (HFIR) from highly enriched uranium (HEU) to low-enriched uranium (LEU) fuel is ongoing at Oak Ridge National Laboratory (ORNL). The presentation will discuss the application of the ORNL core capability in reactor physics modeling and simulation (M\&S) to directly support the ongoing effort on HEU-to-LEU conversion and the design of a compatible HFIR LEU fuel that can be fabricated and meet performance and safety requirements. Details will be provided on the specific challenges for reactor physics analyses and the recent enhancements of the HFIR LEU and HEU computational models and analysis methodologies to address these challenges.
\end{abstract}

\section{BIOGRAPHY}

Germina Ilas is a Senior Research and Development (R\&D) staff member in the Reactor Physics Group of the Reactor and Nuclear Systems Division at ORNL. She received an MS in engineering physics from the University of Bucharest in Romania and a Ph.D. in nuclear engineering from the Georgia Institute of Technology in Atlanta, Georgia. Dr. Ilas has made sustained technical contributions to M\&S for reactor analysis, spent fuel characterization, code validation, and uncertainty assessment at ORNL for the past 10 years, in particular, in the recent years, as the lead for neutronics M\&S to support the HFIR LEU conversion. She has authored over 85 papers and technical reports. Dr. Ilas has contributed to the education of other nuclear engineers and scientists as an instructor at ORNL's SCALE training courses and as a mentor of several postdoc and intern students. 


\title{
Defense Land Fallout Interpretive Code (DELFIC): Application to Post-Detonation Nuclear Forensics
}

\author{
Vince Jodoin \\ Group Leader, Nuclear Security Modeling \\ Oak Ridge National Laboratory \\ jodoinvj@ornl.gov \\ 865.574 .0420 \\ http://web.ornl.gov/sci/nsed/rnsd
}

\begin{abstract}
The talk will review the application of DELFIC to the National Technical Nuclear Forensics interagency ground sample collection team. The collection team needed a fast running, portable mission-planning tool to allow them to robustly respond to emerging improvised nuclear device post-detonation situations.

DELFIC is a validated, physics-based, research reference, fallout prediction software package. It has been implemented into the Fallout Planning Tool and is used to predict the expected isotope concentration of fallout, particle sizes, fractionation ratios, dose rate, and integrated dose over the planned collection routes - information vital to ensure quality samples for nuclear forensic analysis while predicting dose to the sample collectors. DELFIC includes dynamic cloud rise, diffusive transport, and output processor modules. It also contains a particle activity module which models the radiochemical fractionation of the condensing elements in the cooling fireball into and onto particles to predict the activity size distribution for a given scenario. DELFIC's cloud rise module produces a definition of the stabilized cloud which accounts for particle settling and advection during cloud rise which causes a physical fractionation of the particles. The use of Google Maps and Google Earth with the DELFIC Fallout Planning Tool provides a familiar, user-friendly interface for mission planning and visualization.
\end{abstract}

\section{BIOGRAPHY}

Dr. Jodoin has over 29 years of service as a professional military nuclear engineer, scientist, professor, research manager, and multiple program area division chief. He has experience in the physics and effects of nuclear weapons, nuclear treaty monitoring, analysis of environmental samples, and proliferation of nuclear weapons. Previously, as an officer in the US Air Force, he performed such assignments as teaching general physics and nuclear engineering and directing national security research. During the past 9 years at ORNL, he has specialized in fallout modeling, nuclear forensics, and characterization of nuclear events. Dr. Jodoin created a multidisciplinary fallout research program at ORNL that capitalized on existing reactor-based source term modeling expertise. It includes research on the physical, chemical, and radiological properties of fallout. Dr. Jodoin provides technical expertise and guidance to DHS/DNDO/NTNFC as a member of their Nuclear Forensics Science Panel. He is an active member of the JOWOG-43 Fallout Working Group and the JOWOG-29 Nuclear Forensics Users Group. 


\title{
Inverse Radiation Transport Methods for Nondestructive Characterization of SNM
}

John Mattingly, Ph.D.

Associate Professor, Nuclear Engineering

North Carolina State University

john_mattingly@ncsu.edu

919.515.0224

http://www.ne.ncsu.edu/faculty/mattingly.html

\begin{abstract}
Nuclear nonproliferation, counterterrorism, emergency response, and forensics all rely on radiation measurements to detect, identify, and characterize special nuclear material (SNM). Furthermore, nondestructive, nonintrusive measurements of SNM typically rely on penetrating gamma and neutron radiation to detect the material's presence, identify its composition, and characterize its configuration. These applications all rely on models that can be used to infer the properties of SNM from its measured radiation signatures. Inverse radiation transport is an analysis technique that employs transport models of the radioactive material to quantitatively estimate properties including radioactivity, isotopic composition, shielding, and subcriticality. John Mattingly will describe inverse transport analyses applied to gamma and neutron measurements of SNM and demonstrate their application to the characterization of SNM with emphasis on applications in nuclear security.
\end{abstract}

\section{BIOGRAPHY}

John Mattingly joined the North Carolina State University (NCSU) Department of Nuclear Engineering faculty as an Associate Professor in June 2011. His research program is focused on applications of radiation detection to nuclear security missions, including nuclear nonproliferation, counterterrorism, emergency response, and forensics. He and his students work together to develop radiation measurement and analysis techniques to detect and characterize special nuclear material (SNM). Prior to joining the NCSU faculty, Dr. Mattingly worked for 15 years at Sandia National Laboratories (SNL) and Oak Ridge National Laboratory (ORNL) developing and deploying radiation measurement systems for SNM detection and characterization. His accomplishments include co-development of the Gamma Detector Response and Analysis Software (GADRAS) used by numerous agencies in the United States and abroad for rapid analysis of gamma spectrometry measurements of SNM and co-development of the Blend-Down Monitoring System (BDMS) used to monitor the down-blending of Russian highly enriched uranium (HEU) in the US-Russia HEU Purchase Agreement. He has personally conducted hundreds of measurements of SNM in fully assembled nuclear weapons and nuclear weapons components and unclassified, subcritical assemblies of SNM. He also served as an on-call emergency response spectroscopic analyst for the US DOE/NNSA and DHS/DNDO for 5 years during his time at SNL. 


\title{
iFLEX Method for On-the-Fly Detector Calculations
}

\author{
Farzad Rahnema \\ Georgia Power Distinguished Professor and Chair \\ Nuclear and Radiological Engineering and Medical Physics Program, \\ Georgia Institute of Technology \\ farzad@gatech.edu \\ 404.894.3731 \\ http://crmp.gatech.edu/
}

\begin{abstract}
The Monte Carlo method has been widely used in modeling particle transport in radiation detection systems. It is well known that long run times may be required to achieve adequate statistical precision with stochastic methods in computing pulse height tallies, depending on the size of the system modeled, the degree of self-attenuation, and levels of penetration. Therefore inefficiency becomes a prominent issue in achieving computationally inexpensive simulations. For example, in interrogation problems where rapid scenario analysis is essential for forecasting the performance of radiation detection systems, alternate methods are typically desirable.

The incident flux response expansion (iFLEX) method was recently developed in the Computational Reactor and Medical Physics (CRMP) Laboratory at Georgia Tech to accelerate the traditional method of pulse height tally calculation for applicability in detectors. While employing a Monte Carlo method, this new pulse height tally response expansion method achieves on-the-fly computational speed with Monte Carlo accuracies. Characteristically, given a particular geometry and composition for a detector, the Monte Carlo method requires a new simulation for each incident flux. In the iFLEX method, Monte Carlo simulations are utilized to construct response functions that are dependent only on the geometry and composition of the detector, and therefore they can be precomputed as the method's library. Once the incident flux is known, this library is used to construct the pulse height tally via superposition. This workshop will introduce the participants to the iFLEX method based on incident flux response expansion theory for coupled electron/photon transport in detectors and provide a demonstration of the code. The demonstration will showcase multiple iFLEX calculations in real time and compare the results to the results of the same calculation performed in the stochastic transport code MCNP.
\end{abstract}

\section{BIOGRAPHY}

Dr. Rahnema is Georgia Power Company Distinguished Professor and Chair of the Nuclear and Radiological Engineering and Medical Physics Programs at the Georgia Institute of Technology. He also holds an appointment at Emory University School of Medicine as an Adjunct Professor of Radiation Oncology.

Dr. Rahnema received his $\mathrm{PhD}$ in nuclear engineering from the University of California-Los Angeles (UCLA). He joined Georgia Tech in 1992 and was at General Electric Nuclear Energy's nuclear methods development group from 1981-1992. His responsibility included GE's 3-D Nuclear/Thermal Hydraulics BWR Core Simulator PANACEA used for design, monitoring, and prediction of BWR cores.

Dr. Rahnema is a Fellow of the American Nuclear Society (ANS) and Chair of the Honors and Award Committee of the ANS Mathematics and Computation Division (MCD). He is a past Chair of the MCD (two times), the Reactor Physics Division (RPD) and the current Vice Chairman and the founding Chairman of the Board of Directors of the Southeast Universities Nuclear Reactors Institute for Science and Education (SUNRISE). He is also director of the Computational Reactor and Medical Physics Laboratory at Georgia Tech. 


\title{
The SCALE Code System
}

Bradley T. Rearden, Ph.D.

Manager, SCALE Code System

Oak Ridge National Laboratory

reardenb@ornl.gov

865.574.6085

http://scale.ornl.gov

\begin{abstract}
SCALE is a widely used suite of tools for nuclear systems modeling and simulation that provides comprehensive, verified and validated, user-friendly capabilities for criticality safety, reactor physics, radiation shielding, and sensitivity and uncertainty analysis. With over 6100 users in 54 nations, regulators, licensees, and research institutions around the world apply SCALE for nuclear safety analysis and design. SCALE provides a "plug-and-play" framework that includes three deterministic and three Monte Carlo radiation transport solvers that can be selected based on the desired solution and coupled with other tools to form a comprehensive analysis sequence for applications such a used fuel characterization and deep penetration shielding analysis. SCALE includes the latest nuclear data libraries for continuous-energy and multigroup radiation transport as well as activation, depletion, and decay calculations. SCALE's graphical user interfaces assist with accurate system modeling, visualization, and convenient access to desired results. The upcoming release of SCALE 6.2 will provide several new capabilities and significant improvements in many existing features, especially with expanded continuous-energy Monte Carlo capabilities for criticality safety, shielding, depletion, and sensitivity and uncertainty analysis as well as convenient methods for used fuel characterization. An overview of the capabilities of SCALE will be provided with emphasis on new features for SCALE 6.2.
\end{abstract}

\section{BIOGRAPHY}

Brad Rearden is the manager of the SCALE code system. With over 15 years of experience in the development of state-of-the art computational tools and data for nuclear safety analysis and design, Rearden has led the SCALE team since 2009, realizing measurable gains in quality, advanced features, and global reach. Rearden is an internationally recognized expert in the area of sensitivity and uncertainty analysis and earned a Ph.D. in nuclear engineering from Texas A\&M University. 


\title{
Applying Spent Nuclear Fuel Modeling to Safeguards Development
}

\author{
Steve Skutnik \\ Assistant Professor \\ University of Tennessee \\ sskutnik@utk.edu \\ 865.974.2212
}

\begin{abstract}
A vital foundation to the development of safeguards for advanced nuclear fuel cycles is in the development of high-fidelity source term models for nuclear fuel throughout the fuel cycle. By linking together advanced modeling and simulation in nuclear fuel depletion analysis (through tools like ORIGEN) and radiation transport (via packages like MCNP), it is possible to develop rigorous computational models that allow for rapid scoping and prototype studies of advanced safeguard systems. Given the complexity and expense of real-world testing under the range of anticipated fuel and operating conditions, the development of high-quality models based upon validated simulations is essential to the screening and development of new safeguards techniques for advanced fuel cycle processes, such as aqueous and electrochemical reprocessing facilities. This talk will provide an overview of some of the tools and techniques that have been designed to meet this challenge, including recent work on advanced safeguards techniques such as Hybrid K-Edge Densitometry for in situ assay of plutonium and other actinides as well as new tools to enable more detailed modeling assessments of intact used nuclear fuel assemblies.
\end{abstract}

\section{BIOGRAPHY}

Dr. Steven Skutnik is an assistant professor of nuclear engineering at the University of Tennessee. Prior to joining the faculty at UT in 2012, he worked as a postdoctoral research associate in the Reactor Physics group in the Reactor and Nuclear Systems Division at ORNL. During this time, Dr. Skutnik contributed to the modernization of the ORIGEN nuclear fuel depletion code and led the development of the ORIGAMI interface to ORIGEN for nuclear fuel assembly depletion modeling, which has been used both for the Next Generation Safeguards Initiative's spent fuel "working standards” modeling as well as by the UNF ST\&NDARDS tool used by the Used Fuel Decision and Disposition Group to analyze used nuclear fuel source terms in dry storage conditions. He received his Ph.D. in nuclear engineering in 2011 from North Carolina State University. 


\title{
Immersive Environment Development for Training
}

Josh Tackentien

Scientific Associate - Task Monitor

Brookhaven National Laboratory

Tackentien@bnl.gov

631.344.2854

\begin{abstract}
Immersive environments are increasingly demonstrating their utility for a number of nuclear safeguards, nuclear safety, and nuclear and physical security applications. Although training is an obvious use, the immersive (or sometimes called virtual) environment allows the user to "visit" nuclear facilities and sites that might have access restrictions because of security, high radiation, or other hazards and are difficult and expensive to visit. An immersive environment can also be quickly reconfigured to study various scenarios, processes, and other what-if situations, which can aid in planning and the design of new facilities or evaluate safeguards, safety, and/or security measures before they are implemented. As the International Atomic Energy Agency (IAEA), other international organizations, state authorities, industry, and academia continue development and use of immersive environments and other electronic training technologies, more and more applications can be envisioned. Immersive environments are not a direct or always a desirable replacement for hands-on learning; however, the demand for electronic training media, particularly immersive environments, will grow. The resulting increase of system features and libraries presents opportunities to shorten development time frames, reduce costs, and increase availability of immersive environments for a wider audience looking to balance the need for quality training with limited resources. Substantial time and cost savings can be realized by the sharing of raw immersive environment assets among developers and organizations with these training needs. This paper will explore potential guidelines, criteria, and mechanisms for such cooperation.
\end{abstract}

\section{BIOGRAPHY}

Mr. Tackentien has worked for more than 7 years as a Task Monitor for the International Safeguards Project Office at Brookhaven National Laboratory. He has been responsible for the oversight of dozens of United States Support Program tasks to the International Atomic Energy Agency. This includes over 4 years' experience in oversight of all USSP sponsored IAEA training courses. Mr. Tackentien has been the USSP coordinator for task B.109 "Virtual Reality Tools for Training” and has worked closely with the IAEA and contractor Applied Research Associates to support the successful development of the IAEA's Pressurized Heavy Water Reactor virtual reality model. 


\title{
Modeling of Enrichment Cascades
}

\author{
Charles Weber \\ Research Staff \\ ORNL, Reactor and Nuclear Systems Division \\ webercf@ornl.gov \\ 865.576 .4475 \\ http://web.ornl.gov/sci/nsed/rnsd/group_nsm.shtml
}

\begin{abstract}
Modeling of uranium enrichment is helpful in determining if enrichment plants are operating according to declaration, or if undeclared facilities are operating. This presentation will describe the operation of enrichment cascades and how models might benefit inspectors of enrichment facilities. The focus will be on ideal cascade models, but extensions to include more complex models will be mentioned briefly. The models are applicable to both gaseous diffusion and gas centrifuge operations, but dynamics of individual machines or stages will not be emphasized. The discussion will include basic assumptions, isotopic balances, input requirements, output of calculations, and applications to enrichment scenarios.
\end{abstract}

\section{BIOGRAPHY}

Dr. Charles F. Weber has over 36 years of experience in nuclear chemical engineering and applied mathematics. He received a B.A. (Mathematics, 1975), M.S. (Mathematics, 1979), and Ph.D. (Chemical Engineering, 1998), all from the University of Tennessee. He has expertise in many areas of applied mathematics, including numerical analysis, optimization, scientific programming, statistics, and inverse problems. He has applied these skills in various areas of nuclear chemistry and nuclear chemical engineering, such as inverse heat conduction, parameter estimation in chemical kinetics and thermodynamics, inverse depletion/decay modeling, and generalized modeling of enrichment cascades. In addition, he has contributed to several studies of fallout transport during a hypothetical urban nuclear detonation, focusing on the chemical and physical behavior of fallout particles. Dr. Weber has been the principal investigator on a number of projects for NA-22, the Department of Defense, Department of Energy, the Nuclear Regulatory Commission, and the International Atomic Energy Agency. 


\title{
Evolution of Nonproliferation and Safeguards
}

\author{
Michael Whitaker \\ Group Leader, International Safeguards Group \\ Oak Ridge National Laboratory \\ whitakerjm@ornl.gov \\ 865.576.1682
}

\begin{abstract}
The discussion of nonproliferation began in the 1940s and implementation has continually evolved ever since. US President Eisenhower's “Atoms for Peace” 1953 speech included a call for the creation of an International Atomic Energy Agency (IAEA). An IAEA was created in 1957, and this presentation will describe the organization and how its roles and responsibilities have been expanded over time to address the nonproliferation challenges of the day.
\end{abstract}

\section{BIOGRAPHY}

Michael Whitaker is the manager of the International Safeguards Program at the Oak Ridge National Laboratory (ORNL). He has been involved in international safeguards for over 30 years. He began his career in 1981 as a university student working in the Operations Analysis and Planning Division at the Oak Ridge Gaseous Diffusion Plant (ORGDP). He has worked 10 years at ORGDP, 10 years at the Y12 National Security Complex, and the last $\sim 15$ years at ORNL.

Throughout his career he has been involved in a wide variety of IAEA-related activities including the application of IAEA safeguards on nuclear materials at US nuclear facilities from 1994 to present, developing inspection and data evaluation tools for the IAEA, conducting training for IAEA inspectors, and assisting IAEA member countries such as Argentina, Brazil, and South Africa prepare for and implement IAEA safeguards at their nuclear facilities. He continues to serve as the ORNL coordinator for the US Support Program for IAEA safeguards.

Mr. Whitaker holds a B.S. in mechanical engineering and an M.S. in industrial engineering (engineering management) from the University of Tennessee. He is a senior member of the Institute of Nuclear Materials Management (INMM) and is the current Chair of the INMM International Safeguards Technical Division. 


\title{
An Index of Modeling and Simulation Activities at ORNL
}

\author{
Jessica White-Horton \\ R\&D Scientist \\ Oak Ridge National Laboratory \\ whitejl@ornl.gov \\ 865.574.1075
}

\begin{abstract}
A 2008 review of nuclear safeguards by the Department of Energy's (DOE) National Nuclear Security Administration (NNSA) states that US support for the international safeguards system needed a revitalization of safeguards technology, human resources, and human capital development. To address this problem, NNSA launched the Next Generation Safeguards Initiative (NGSI) to develop the policies, concepts, technologies, expertise, and infrastructure necessary to sustain the safeguards system as its mission evolves over the next 25 years.

Modeling and simulation (M\&S), one of the many ideas mentioned in the 2008 paper, focuses on the usefulness of computer and physical models in elucidating many of the complex occurrences in nuclear operations. The International Safeguards Group within the Nuclear Security and Isotope Technology Division at Oak Ridge National Laboratory (ORNL) began working to catalog M\&S projects at ORNL in January 2010 with the goal of cataloging projects that involve the nuclear fuel cycle and that can be adapted to safeguards applications.

The staff scheduled interviews with scientists from a variety of divisions across ORNL to learn more about their respective tasks and created a quad chart to summarize the characteristics of each specific project. These quad charts were then placed into a Microsoft Access database, which will eventually be published for site-wide access. The staff anticipates that the database will eventually span the entire DOE complex, establishing better communication and integration between the national laboratories and reducing the risk of stovepiping. The database will be continuously updated and provide an accessible user-friendly interface.

On completion of the ORNL section of the database, the next step is to reach out to the other DOE national laboratories and catalog projects of a similar nature. The team's goals for the future include updating the existing data as projects advance, further enhancing database functionality, and adding data sources as they become available. The database will serve not only as an excellent reference tool for people beginning new projects in an M\&S area but also as an educational resource to teach others the importance of M\&S.
\end{abstract}

\section{BIOGRAPHY}

Jessica White-Horton is a research and development staff member in the International Safeguards group at Oak Ridge National Laboratory in the Nuclear Security and Isotope Technology Division. She has a B.A. in foreign language and chemistry from McGill University in Montreal, QC, a M.S. in physics and chemistry from the University of Tennessee-Knoxville, and is a 2012 fellow of the World Nuclear University and an alumnus of the International School of Nuclear Law. Her major work focus is in international safeguards and nonproliferation, but her interests include all areas defined under the $3 \mathrm{~S}$ concept (safeguards, safety, and security). 


\title{
Nuclear Fuel Cycle Facilities Overview
}

Andrew Worrall

Senior Scientist

Oak Ridge National Laboratory

worralla@ornl.gov

865.576.9369

www.ornl.gov

\begin{abstract}
The nuclear fuel cycle involves a number of process steps including mining and milling, conversion, enrichment, fuel fabrication, electricity production, interim cooling, and disposal. There are also a number of options as to what to do with the spent fuel after irradiation including direct disposal (the "open fuel cycle") or separations and subsequent recycle of several streams including plutonium, uranium and potentially minor actinides (the "closed fuel cycle"). The talk will briefly describe each of the process steps, as well as outline the reasons for reprocessing and recycle, and how the different reactor designs can affect the plutonium quality produced. In addition, the proliferation resistance and physical protection considerations for a given fuel cycle will be highlighted, including how tools such as ORION (linked with ORIGEN) can be used to analyze and assess fuel cycles from an operational and safeguards perspective. The objective of the talk is to provide an insight into the diversity of the fuel cycles available and how the facilities, processes, and materials are diverse, requiring different inspection regimes and detection techniques in order to highlight the role of modeling and simulation in the nuclear fuel cycle.
\end{abstract}

\section{BIOGRAPHY}

Andrew has more than 20 years professional international experience working and leading in fields related to reactor physics, core design, plutonium disposition, fuel development and fuel cycle analysis. He joined ORNL 21/2 years ago, and prior to that was the "Technical Authority for Reactors and Fuels" at the UK National Nuclear Laboratory where he was responsible for the overall technical direction and delivery of all reactor and fuel-related programmes. At ORNL Andrew directs and manages research programs in fuel, reactor, and fuel cycle analysis. He is actively involved in a number of US Department of Energy (DOE) and National Nuclear Security Administration (NNSA) programs associated with fuel and reactor analysis, and fuel cycle assessment. Specific programs that Andrew leads on include accidenttolerant fuels, spent fuel monitoring and management from a safeguards and security context, evaluation and screening of future US fuel cycle options, and international plutonium management programs with Japan, France, and the UK. He is a Chartered Physicist (CPhys) and a Fellow of the Institute of Physics (FInstP) in the UK. He is also a Royal Academy of Engineering Visiting Professor of Nuclear Engineering at the University of Birmingham in the UK. 